\title{
A 20-Year Climatology of a NICAM AMIP-Type Simulation
}

\author{
Chihiro KODAMA, Yohei YAMADA, Akira T. NODA \\ Japan Agency for Marine-Earth Science and Technology, Yokohama, Japan \\ Kazuyoshi KIKUCHI \\ International Pacific Research Center, University of Hawaii, Hawaii, USA \\ Yoshiyuki KAJIKAWA \\ RIKEN Advanced Institute for Computational Science, Kobe, Japan \\ Tomoe NASUNO \\ Japan Agency for Marine-Earth Science and Technology, Yokohama, Japan
}

Tomohiko TOMITA

Graduate School of Science and Technology, Kumamoto University, Kumamoto, Japan

Tsuyoshi YAMAURA

RIKEN Advanced Institute for Computational Science, Kobe, Japan

\section{Hiroshi G. TAKAHASHI}

Tokyo Metropolitan University, Hachioji, Japan

Japan Agency for Marine-Earth Science and Technology, Yokohama, Japan

\section{Masayuki HARA}

Center for Environmental Science in Saitama, Kazo, Japan

\section{Yoshio KAWATANI}

Japan Agency for Marine-Earth Science and Technology, Yokohama, Japan

\section{Masaki SATOH}

Atmosphere and Ocean Research Institute, The University of Tokyo, Kashiwa, Japan Japan Agency for Marine-Earth Science and Technology, Yokohama, Japan

and

\section{Masato SUGI}

Meteorological Research Institute, Tsukuba, Japan

(Manuscript received 6 November 2014, in final form 17 March 2015)

\footnotetext{
Corresponding author: Chihiro Kodama, Department of Seamless Environmental Prediction Research, Japan Agency for Marine-Earth Science and Technology, 3173-25 Showa-machi, Kanazawa-ku, Yokohama 236-0001, Japan E-mail: kodamac@jamstec.go.jp (C)2015, Meteorological Society of Japan
} 


\begin{abstract}
A 20-year integration by the nonhydrostatic icosahedral atmospheric model (NICAM) with a $14 \mathrm{~km}$ mesh was conducted for the first time to obtain a climatological mean and diurnal to interannual variability of a simulated atmosphere. Clouds were explicitly calculated using a cloud microphysics scheme without cumulus convection scheme. The simulation was performed under the atmospheric model intercomparison project-type conditions, except that sea surface temperature was nudged toward observed historical values using the slab ocean model. The results are analyzed with a focus on tropical disturbances, including tropical cyclones (TCs) and the MaddenJulian oscillation (MJO).

NICAM simulates many aspects of atmospheric climatological mean state and variability. The geographical distributions of precipitation, including interannual, seasonal, and diurnal variations, are well reproduced. Zonal mean basic states, clouds, and top-of-atmosphere radiation are qualitatively simulated, though some severe biases such as underestimated low clouds, shortwave reflection, warmer surface, and tropical upper troposphere exist.

TCs and MJO are the main focus of the simulation. In the simulation, TCs are detected with the objective thresholds of maximum wind speed due to the realistic intensity of simulated TCs. The seasonal march of TC genesis in each ocean basin is well simulated. The statistical property of the MJO and tropical waves is well reproduced in the space-time power spectra, consistent with previous NICAM studies. This implies that the stratospheric variability is also reproduced, as partially revealed in this study. Asian monsoon analysis shows that climatological western North Pacific monsoon onset occurs near the observed onset, and that the Baiu front is reproduced to some extent. Some significant model biases still exist, which indicates a need for further model improvements. The results indicate that a high-resolution global nonhydrostatic model has the potential to reveal multiscale phenomena in the climate system.
\end{abstract}

Keywords global non-hydrostatic model; climate simulation; moist process; tropical cyclone; Madden-Julian oscillation and tropical wave; Asian monsoon

\section{Introduction}

Moist processes play a major role in maintaining the Earth's climate system. They couple with largescale circulation by redistributing energy, angular momentum, and water in the atmosphere. For example, radiation budgets at the top-of-atmosphere (TOA) strongly depend on cloud properties associated with moist processes. Moist convection triggers various types of atmospheric waves, which modify the basic state of the troposphere and middle atmosphere through wave-mean flow interaction. Most extreme disaster events, such as tropical cyclones (TCs) and intense rainfall, are closely associated with moist convection.

Despite the scientific and social importance of moist processes, they are parameterized in most climate models, which causes ambiguity and restricts our ability to adequately simulate the climate system (Stevens and Bony 2013). Most current climate models are performed with a horizontal resolution of $O(100 \mathrm{~km})$, with cumulus convection parameterized as a sub-grid scale phenomenon. Cumulus convection scheme may delay the improvement and reliability of present and future climate simulations. This is of specific importance in TC simulations because their statistics strongly depend on the cumulus convec- tion scheme (Murakami et al. 2012) as well as horizontal resolution (Camargo 2013). Zhao et al. (2012) demonstrated the sensitivity of global TC frequency to parameters in convection scheme and dynamics formulation. Most climate models do not capture the eastward propagation and amplitude of the MaddenJulian oscillation (MJO) (Hung et al. 2013) — a dominant intraseasonal variability in the tropics, and many authors suggested the relationship between the cumulus convection scheme and the simulated MJO (see references in Hung et al. 2013). In addition, uncertainty in climate sensitivity among climate models is chiefly attributable to the different response of the clouds to global warming (Cess et al. 1989; Soden and Held, 2006; Vial et al. 2013; Zhao, 2014).

Increasing spatial resolution is a natural approach to improving climate simulations (Shukla et al. 2009). Following the atmospheric model intercomparison project (AMIP) (Gates 1992) protocol, Mizuta et al. (2006, 2012) and Kinter et al. (2013) conducted climate simulations with a horizontal resolution of $16-20 \mathrm{~km}$ using a cumulus convection scheme. Another strategy used to treat moist processes in global climate model is the multiscale modeling framework (MMF) (Grabowski 2001; Khairoutdinov and Randall 2001), in which two-dimensional (2D) cloud resolving model is locally operated in place of 
the cumulus convection scheme. Khairoutdinov et al. (2008) conducted an AMIP-style simulation using MMF and demonstrated its benefits for simulating the MJO and tropical waves. Such a new type model is expected to simulate atmospheric phenomena such as tropical disturbances even more realistically if its simulated mean state is improved with the consideration of interaction mechanisms between mean state and phenomena (Inness et al. 2003; Sperber and Annamalai 2008; Kim et al. 2009).

We conduct the first-ever climate simulation using a $14 \mathrm{~km}$ mesh nonhydrostatic icosahedral atmospheric model (NICAM) (Tomtia and Satoh 2004; Satoh et al. 2008, 2014) with an explicit cloud microphysics scheme. Such explicit treatment of moist processes without a cumulus convection scheme might significantly improve present climate simulation performance and the reliability of future climate projections. In particular, we investigate the climatological mean state and diurnal, seasonal, and interannual variability in a 20-year NICAM simulation to evaluate the simulation performance in reproducing the present climate.

A much finer resolution of NICAM better resolves individual convection (Miyamoto et al. 2013). However, according to previous studies using output from seasonal-scale experiments (Noda et al. 2010, 2012; Kodama et al. 2012, and the references therein), the gross features of the convection and clouds are practically simulated by the $14 \mathrm{~km}$ mesh model. Holloway et al. (2013) showed that a $12 \mathrm{~km}$ mesh model with an explicit convection scheme reproduced the MJO well. Pauluis and Garner (2006) investigated the relationship between horizontal resolution and convection statistics under the radiative-convective equilibrium. They suggested that the statistical behaviors of the deep convection and cirrus cloud remain almost unaffected as the horizontal mesh increases from 16 to $2 \mathrm{~km}$, though they showed a strong relation between horizontal resolution and shallow convection. As a milestone toward a true "convection resolving" climate simulation, it is of great interest to evaluate "convection permitting" climate simulation in an attempt to develop and improve a global nonhydrostatic model with an explicit cloud microphysics scheme.

Previous seasonal-scale experiments have shown that NICAM has a significant advantage for simulating TCs and the MJO. NICAM simulates the TC intensity (Yamada and Satoh 2013) and enables us to comprehensively discuss the TC structure (Miyamoto et al. 2014). Miura et al. (2007) and Miyakawa et al. (2014) showed that NICAM sufficiently simu- lates the MJO, which is disreputable for its elusiveness in conventional GCMs. Miyakawa et al. (2014) conducted a series of NICAM experiments with 54 ensemble members and confirmed the NICAM's ability to simulate the evolution of the MJO over approximately 30 days, whereas most conventional GCMs cannot provide a useful forecast skill beyond two weeks (Matsueda and Endo 2011). An adequate representation of the MJO leads to a better representation of TC genesis that occurs with the MJO, which is also reproduced in NICAM (Fudeyasu et al. 2008; Oouchi et al. 2009; Taniguchi et al. 2010). High horizontal resolution simulations also produce better representation of diurnal precipitation cycles (Sato et al. 2009; Dirmeyer et al. 2011; Noda et al. 2012). We also expect that NICAM sufficiently simulates many other phenomena in the climate system. In this study, we subjectively choose several important atmospheric phenomena in addition to TC and the MJO to evaluate NICAM's capability to simulate overall climate over a 20 -year period.

The remainder of this paper is as follows. In Section 2, we describe the experimental design and observational datasets to be compared with the model output. In Section 3, the reproducibility of global basic fields such as precipitation (3.1), radiation and clouds (3.2), zonal mean state (3.3), and surface air temperature (3.4) are presented. In Section 4, the individual phenomena results are described, especially TCs (4.1), the MJO and tropical waves (4.2), the Asian monsoon (4.3), the Baiu front (4.4), diurnal precipitation cycles (4.5), and lower stratospheric variability (4.6). Discussion-including future model improvements - is presented in Section 5. Finally, conclusions are provided in Section 6. Further analysis of individual topics will be discussed elsewhere.

\section{Method}

\subsection{Observational datasets}

Table 1 shows a list of observational datasets used for simulation and evaluation. The spatiotemporal resolutions are consistent between the observed and simulated data for each figure.

\subsection{Experimental design}

NICAM (Tomita and Satoh 2004; Satoh et al. $2008,2014)$ is a nonhydrostatic atmospheric model developed for ultra-high resolution simulations. In this study, the 2012 version (hereafter, NICAM.12) was used. Table 2 shows the descriptions of the physics schemes implemented in NICAM.12. Water vapor, liquid cloud, ice cloud, rain, snow, and graupel 
Table 1. List of observational dataset

\begin{tabular}{|c|c|c|c|}
\hline Short name & Full name & Resolution & Reference \\
\hline CERES & $\begin{array}{l}\text { Clouds and Earth's Radiant Energy System } \\
\text { (CERES) Energy Balanced and Filled } \\
\text { (EBAF) TOA Edition } 2.8(\text { Ed } 2.8)\end{array}$ & $1.0^{\circ} \times 1.0^{\circ}$, monthly-mean & Loeb et al. (2009) \\
\hline CLAUS & $\begin{array}{l}\text { Brightness temperature data from the cloud } \\
\text { archive user service (CLAUS) }\end{array}$ & $0.5^{\circ} \times 0.5^{\circ}, 3$-hourly & Hodges et al. (2000) \\
\hline CMAP & $\begin{array}{l}\text { Climate Prediction Center (CPC) Merged } \\
\text { Analysis of Precipitation }\end{array}$ & $2.5^{\circ} \times 2.5^{\circ}$, monthly-mean & Xie and Arkin (1997) \\
\hline ERA-40 & $\begin{array}{l}\text { European Centre for Medium-Range } \\
\text { Weather Forecasts (ECMWF) Reanalysis-40 }\end{array}$ & $2.5^{\circ} \times 2.5^{\circ}, 6$-hourly & Uppala et al. (2005) \\
\hline ERA-I & $\begin{array}{l}\text { European Centre for Medium-Range } \\
\text { Weather Forecasts (ECMWF) Interim } \\
\text { Reanalysis }\end{array}$ & $2.5^{\circ} \times 2.5^{\circ}, 6$-hourly & Dee et al. (2011) \\
\hline GPCP & $\begin{array}{l}\text { Global Precipitation Climatology Project } \\
\text { (version 2.2) }\end{array}$ & $\begin{array}{l}2.5^{\circ} \times 2.5^{\circ}, \text { monthly-mean/ } \\
\text { pentad }\end{array}$ & Adler et al. (2003) \\
\hline HadISST & $\begin{array}{l}\text { Hadley Centre Sea Ice and Sea Surface } \\
\text { Temperature dataset }\end{array}$ & $1.0^{\circ} \times 1.0^{\circ}$, monthly-mean & Rayner et al. (2003) \\
\hline IBTrACS & $\begin{array}{l}\text { International Best Track Archive for Climate } \\
\text { Stewardship }\end{array}$ & & Knapp et al. (2010) \\
\hline ISCCP & $\begin{array}{l}\text { International Satellite Cloud Climatology } \\
\text { Project }\end{array}$ & $2.5^{\circ} \times 2.5^{\circ}$, monthly-mean & Rossow and Schiffer (1999) \\
\hline JRA-25 & Japanese 25 -year reanalysis & $1.25^{\circ} \times 1.25^{\circ}, 6$-hourly & Onogi et al. (2007) \\
\hline JRA-55 & Japanese 55-year reanalysis & $1.25^{\circ} \times 1.25^{\circ}, 6$-hourly & Ebita et al. (2011) \\
\hline NOAA & $\begin{array}{l}\text { National Oceanic and Atmospheric Admin- } \\
\text { istration (NOAA) Interpolated outgoing } \\
\text { longwave radiation (OLR) }\end{array}$ & $2.5^{\circ} \times 2.5^{\circ}$, daily & Liebmann and Smith (1996) \\
\hline TRMM-PR & $\begin{array}{lcc}\text { Tropical } & \text { Rainfall Measuring } & \text { Mission } \\
(\text { TRMM) } & \text { 2A25 product, version } 7 & \end{array}$ & $\begin{array}{l}\text { Converted to } 0.1^{\circ} \times 0.1^{\circ} \\
\text { monthly with diurnal vari- } \\
\text { ation }\end{array}$ & Iguchi et al. (2000) \\
\hline
\end{tabular}

were calculated using a single-moment bulk cloud microphysics scheme (NSW6) (Tomita 2008), and the cumulus convection scheme was not used. The detailed descriptions of NICAM are reviewed by Satoh et al. (2014).

The horizontal resolution of the model used was approximately $14 \mathrm{~km}$ (grid division level 9). Thirty-eight vertical levels were used, extending to a height of $40 \mathrm{~km}$ above the sea level. The interval between each vertical level was increased from 160 $\mathrm{m}$ to $1 \mathrm{~km}$ below $11 \mathrm{~km}$ (25 layers) and to $2 \mathrm{~km}$ below $25 \mathrm{~km}$ (additional 9 layers). The sensitivity of a simulated climate such as cirrus and radiation to the vertical resolution will be discussed in a separate paper (Seiki et al. 2015b). The integration time interval was set to $30 \mathrm{~s}$ over the first five years, and then $60 \mathrm{~s}$ over the remaining term.

The simulation began in June 1, 1978 and was performed for more than 20 years. In this study, the dataset beginning on January 1, 1979 (after 7-month spin-up) and ending December 31, 1998 was used for the analysis, unless otherwise stated. Atmospheric initial conditions were taken from the ERA-40 (Table 1). Monthly mean sea surface temperature (SST) and the sea ice of the HadISST1 (Table 1) were interpolated to initial time for the slab ocean model. To reduce land model initial shock, which could last for several years, land initial conditions were taken from the monthly mean five-year climatology of the $220-\mathrm{km}$ mesh NICAM simulation, which was conducted for 10 years including the five-year spinup. 
Table 2. Physics schemes in NICAM. 12

\begin{tabular}{lll}
\hline \multicolumn{1}{c}{ Physics process } & \multicolumn{1}{c}{ Description } & \multicolumn{1}{c}{ Reference } \\
\hline Cloud microphysics & $\begin{array}{l}\text { NICAM Single-moment Water 6 (NSW6) with top-of- } \\
\text { atmosphere (TOA) radiation tuning }\end{array}$ & Tomita (2008) \\
\hline Cumulus convection & Not used & Sekiguchi and Nakajima (2008) \\
\hline Radiation & mstrnX & $\begin{array}{l}\text { Nakanishi and Niino (2006); } \\
\text { Noda et al. (2010) }\end{array}$ \\
\hline Turbulence & Mellor-Yamada Nakanishi-Niino (MYNN2) & \\
\hline Gravity wave & Not used & \begin{tabular}{l} 
Takata et al. (2003) \\
\hline Land surface
\end{tabular} \\
& Minimal Advanced Treatments of Surface Interaction and & \\
\hline Surface flux (ocean) & Bulk surface flux. & $\begin{array}{l}\text { Louis (1979); surface roughness } \\
\text { following Moon et al. (2007) } \\
\text { and Fairall et al. (2003) }\end{array}$ \\
\hline Ocean model & Single layer slab-ocean & \\
\hline
\end{tabular}

The simulation was performed under the AMIPtype conditions, except that SSTs were nudged toward Taylor-corrected (Taylor et al. 2000) HadISST1 values using the slab ocean model. The nudging relaxation time was 7 days, and the depth of the slab ocean model was set to $15 \mathrm{~m}$. These "AMIP-like" configurations were used instead of those following the strict AMIP protocol because of the better performance of the simulation in terms of the geographical distributions of the precipitation (Appendix A) and the MJO (Grabowski 2006). Sea ice concentration was constrained to the HadISST1 values. The interannual variation of the three-dimensional ozone distribution was obtained from the Meteorological Research Institute chemical transport model (Shibata et al. 2004) monthly mean output of the simulation performed under CCMVal REF2 conditions (Eyring et al. 2008). For each month, five-year running means were applied to obtain ozone data prescribed for the model. The annual mean concentrations of $\mathrm{CO}_{2}, \mathrm{~N}_{2} \mathrm{O}, \mathrm{CH}_{4}$, $\mathrm{CFC11}$, and $\mathrm{CFC} 12$, including interannual variability (Hansen and Sato 2004), were prescribed uniformly globally. Aerosols and 11-year solar cycles were not considered in the simulation.

The model was executed using 640 computing nodes (i.e., 640 CPUs or 5,120 cores) of the $\mathrm{K}$ computer (Yokokawa et al. 2011; Miyazaki et al. 2012), which comprised $7.7 \%$ of the total system. In this case, the total elapsed time (excluding queuing time) is approximately 100 days to achieve the 20 -year simulation. The actual time for the 20 -year simulation is approximately 14 months. We did not face any numerical instability throughout the simulation.

\section{Global basic fields}

\subsection{Precipitation}

Figure 1 shows the seasonal climatological means of the observed and simulated precipitation rates during June-July-August (JJA), September-OctoberNovember (SON), December-January-February (DJF), and March-April-May (MAM). The global mean precipitation rates are quantitatively well simulated compared with GPCP (Table 1) observation, but are slightly overestimated compared with CMAP (Table 1) observation. The distributions of zonal mean precipitation rates and seasonal peak precipitation migration are also captured. The model reproduces greater than observed peak precipitation rates near the intertropical convergence zone (ITCZ). The South Pacific convergence zone is also captured, though its south-eastward extension is underrepresented in the model. A notable double-ITCZ bias exists during SON. The model overestimates precipitation along the coast in the Bay of Bengal and over the tropical Indian Ocean during JJA and underestimates precipitation near the Philippines in both JJA and SON and in the northeastern parts of South America during all seasons.

In seasonal-scale experiments using the previous versions of NICAM, simulated global and low-latitude mean precipitation exceeded those produced by 


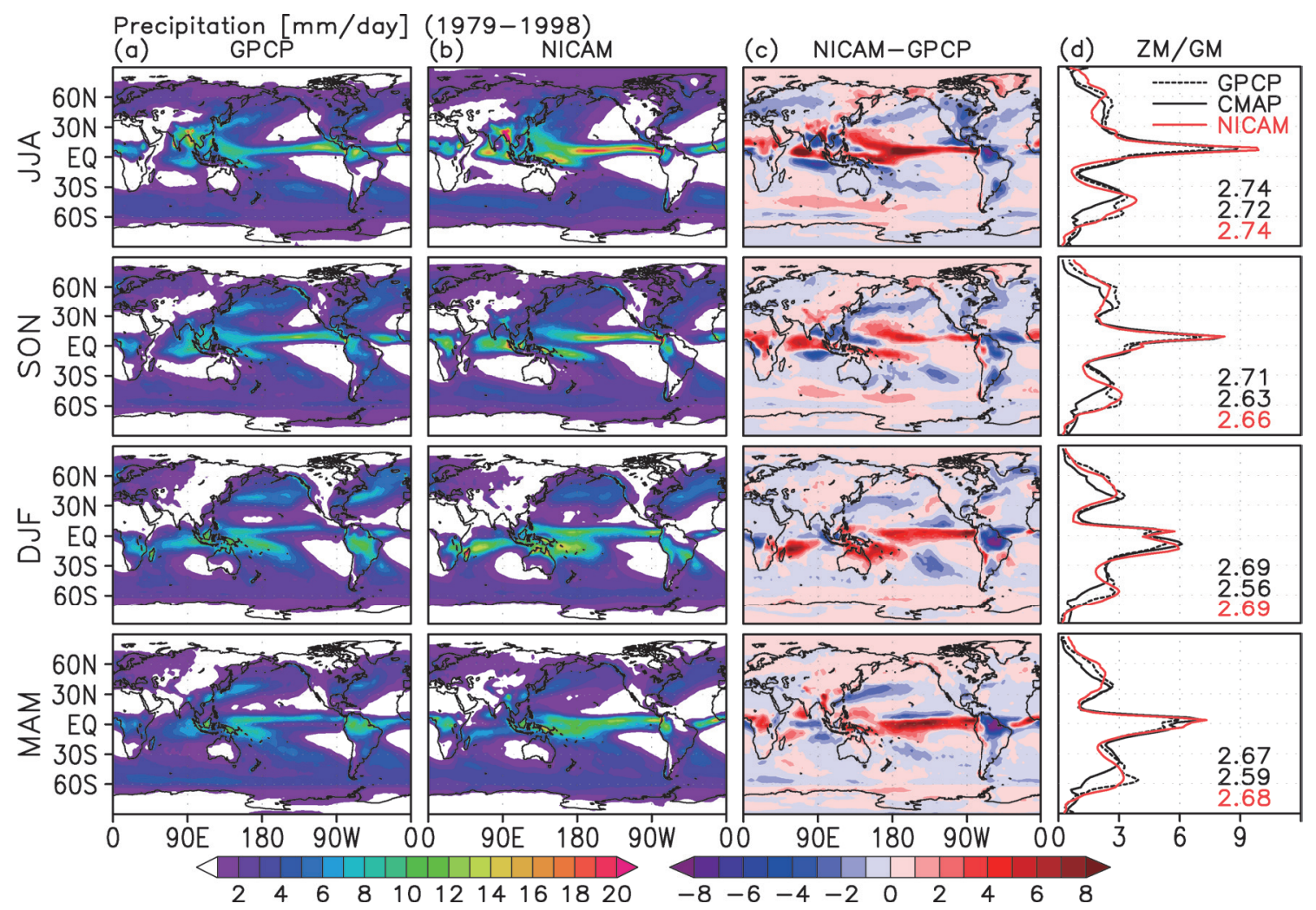

Fig. 1. Seasonal mean climatological precipitation rates in $\mathrm{mm}_{\text {day }}{ }^{-1}$ during JJA, SON, DJF, and MAM analyzed from March 1979 to February 1999 for GPCP (a), NICAM (b), and NICAM - GPCP (c) results. The zonal mean $(\mathrm{ZM})$ and global mean (GM) precipitation rates for GPCP, CMAP, and NICAM are shown in (d). The zonal and global mean values were calculated using grid point values at which the monthly mean GPCP, CMAP, and NICAM data were available.

GPCP by $26 \%$ and $27 \%$, respectively (Noda et al. 2012; Tables 1, 3) ${ }^{1}$. The reduced global mean precipitation bias in this study compared with Noda et al. (2012) is consistent with a decrease in global mean TOA OLR (Fig. 2 in Noda et al. 2010; Fig. 3 in this study). According to the seasonal-scale experiments using NICAM.12 - the version used in this study the simulated global mean precipitation is greater than what is analyzed in GPCP by approximately 10 $\%$ (not shown), indicating that some of the precipitation bias in the previous study arises from model spin-up and/or integration term. Another possible factor that changes simulated global mean radia-

${ }^{1}$ Unlike this study, the global mean precipitation in Noda et al. (2012) was derived without applying latitudinal areal weight. The definition difference does not affect the conclusion that the bias in the global mean precipitation is reduced in this study compared with that in Noda et al. (2012) tion and precipitation is the model update including the cloud microphysics scheme (Grabowski 1998/ NSW6), the land model (bucket model/MATSIRO), and ocean model (fixed SST/slab ocean model). The update of the ocean model configurations, which improves geographical precipitation distribution bias, is discussed in Appendix A.

In the tropics, the El Niño Southern Oscillation (ENSO) mostly governs the interannual variability of the precipitation distribution. Figure 2 shows precipitation response to ENSO. In general, precipitation variation is reasonably captured in response to ENSO-induced SST variation; both the observation and the model show more precipitation over the central to eastern Pacific and less precipitation over the Maritime Continent during the El Niño phase. In NICAM, positive precipitation anomalies are biased eastward with greater amount, and negative anomalies in the northern hemisphere $(\mathrm{NH})$ subtropics are more 


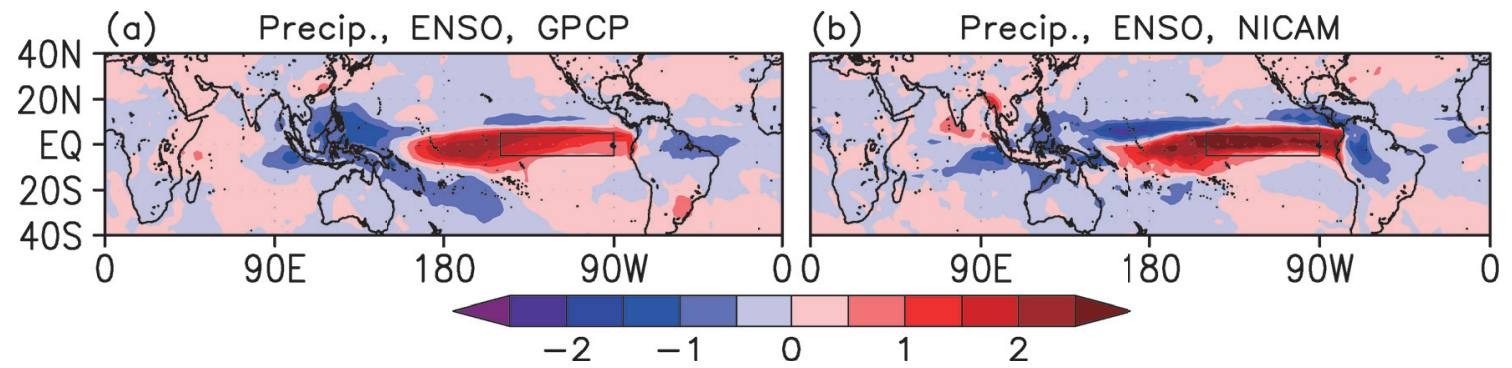

Fig. 2. Precipitation response to El Niño Southern Oscillation (ENSO) during 1979-1998 for GPCP (a) and NICAM (b) results. The monthly mean precipitation rate in $\mathrm{mm} \mathrm{day}^{-1}$ was regressed on ENSO index, which is defined as the departure of the NINO3 $\left(150^{\circ} \mathrm{W}-90^{\circ} \mathrm{W}, 5^{\circ} \mathrm{S}-5^{\circ} \mathrm{N}\right.$; black box) mean SST in $\mathrm{K}$ from its monthly mean climatological value, and the regression coefficient is shown.

TOA ratiation for all seasons $\left[\mathrm{W} / \mathrm{m}^{\wedge} 2\right]$

(a) CERES(01-12)

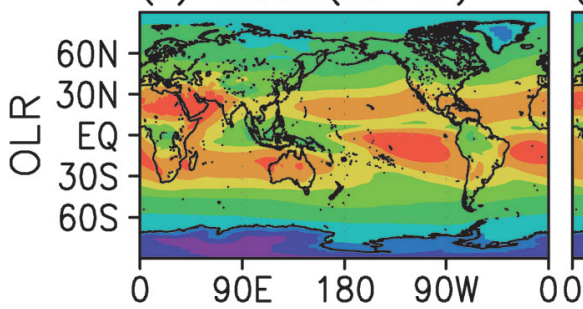

(b) $\operatorname{NICAM}(79-98)$

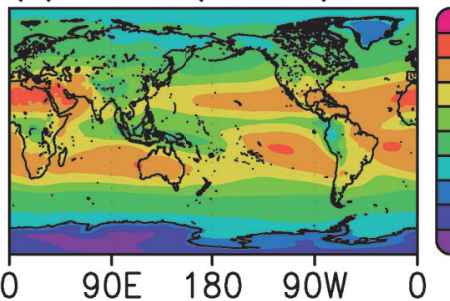

(c) $Z M / G M$
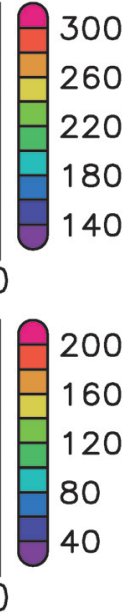
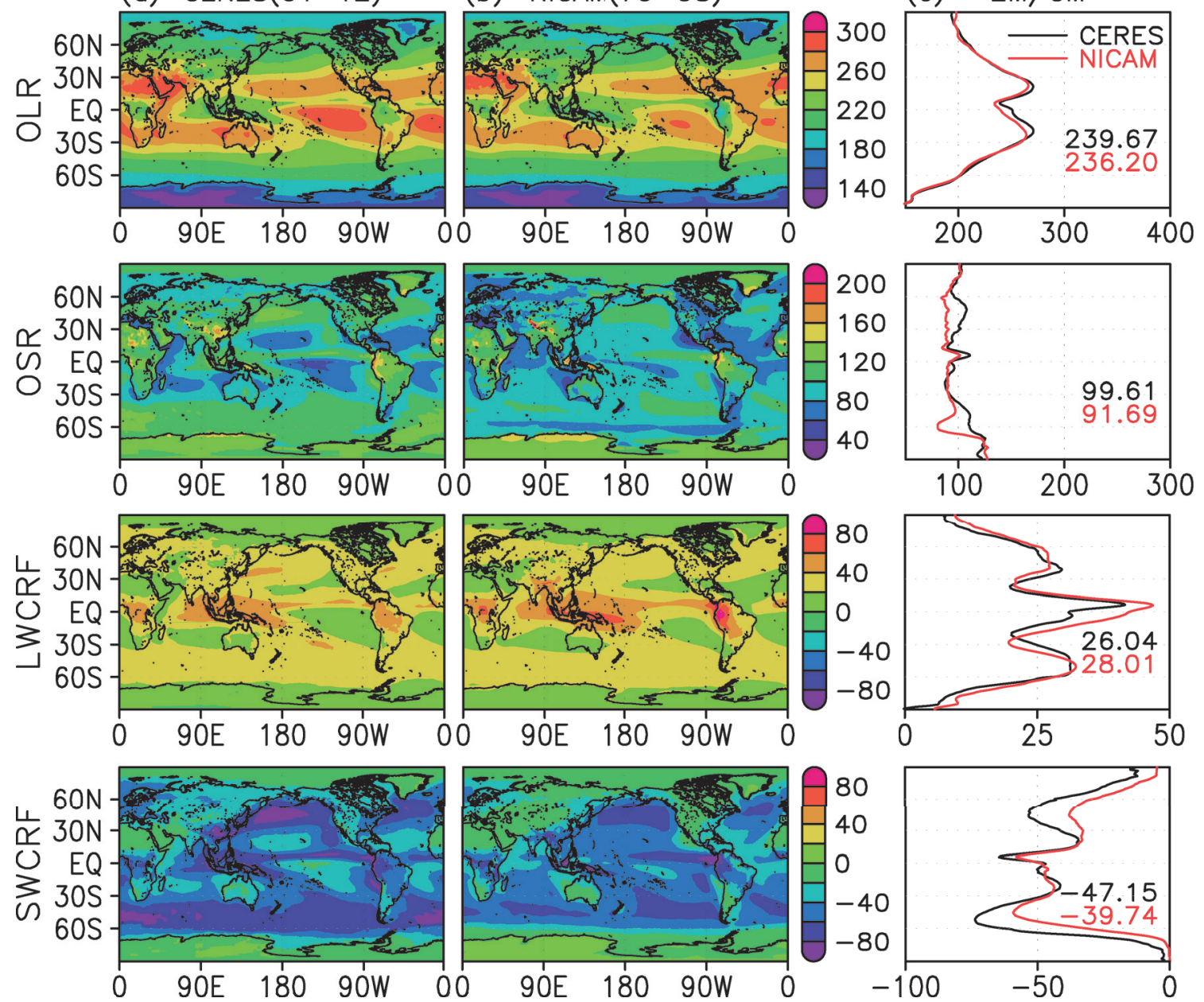

Fig. 3. Annual mean TOA OLR and OSR and longwave and shortwave cloud radiative forcing (LWCRF and SWCRF, respectively) in $\mathrm{W} \mathrm{m}^{-2}$. Positive cloud radiative forcing denotes warming effect for the climate system. CERES (Table 1) data averaged from 2001 to 2012 are shown in (a), and NICAM data averaged from 1979 to 1998 are shown in (b). ZM and GM values for each dataset are shown in (c). 


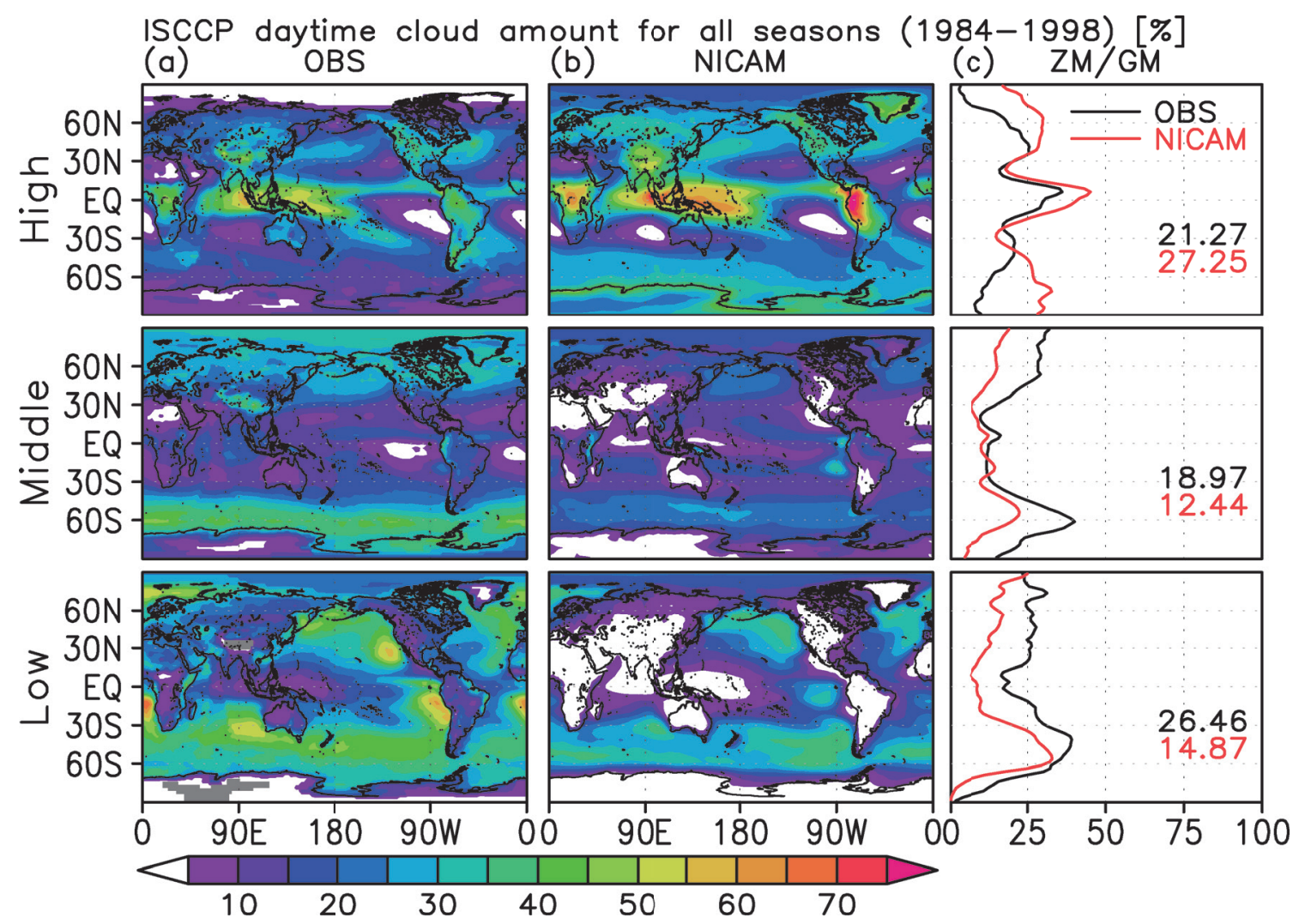

Fig. 4. Annual mean ISCCP daytime cloud amount (\%) for high, middle, and low clouds averaged from 1984 to 1998. The satellite observations are shown in (a), and NICAM with ISCCP simulator results are shown in (b). $\mathrm{ZM}$ and GM values are shown in (c), which were obtained using grid point values at which all the monthly mean satellite data were available.

prominent. The mean state biases (Fig. 1) seem to be related to some of the variability biases such as low variability around the Philippines and high variability along the coast in the Bay of Bengal and over tropical Indian Ocean.

\subsection{Radiation and clouds}

Figures $3 \mathrm{a}$ and $3 \mathrm{~b}$ show the annual mean TOA outgoing longwave radiation (OLR) and outgoing shortwave radiation (OSR). Overall, the distributions of the 2D and zonal mean OLR are well simulated by the model, capturing the position of OLR maxima in the subtropics and OLR minima in the tropics. The simulated OLR is in good agreement with the observed values in the extratropics but lower than observation in the tropics. This leads to the lower global mean OLR bias of $3.47 \mathrm{~W} \mathrm{~m}^{-2}$. OSR is simulated in the tropics but underestimated in the extratropics. Consequently, the simulated global mean OSR is lower than observed values by $7.92 \mathrm{~W} \mathrm{~m}^{-2}$.
Such OLR and OSR biases at the TOA are mostly contributed by longwave cloud radiative forcing (LWCRF) and shortwave cloud radiative forcing (SWCRF), as shown in Figs. 3c and 3d. The global mean LWCRF and SWCRF simulated by the model exceed observations by 1.97 and $7.41 \mathrm{~W} \mathrm{~m}^{-2}$, respectively, and these biases are mainly contributed by lower latitude LWCRF and higher latitude SWCRF.

Figure 4 shows the annual mean climatology of ISCCP (Table 1) cloud amount for high, middle, and low clouds. The ISCCP simulator (Klein and Jakob 1999; Webb et al. 2001) was used to estimate the ISCCP cloud amount in the model. The model qualitatively reproduces the geographical distributions of global clouds. High clouds are frequently observed in the tropics and midlatitudes, and the model captures this to some extent. The model quantitatively overestimates high cloud amount at most latitudes, which leads to the LWCRF bias in the tropics (Fig. 3). In the extratropics, the magnitude of the positive LWCRF 


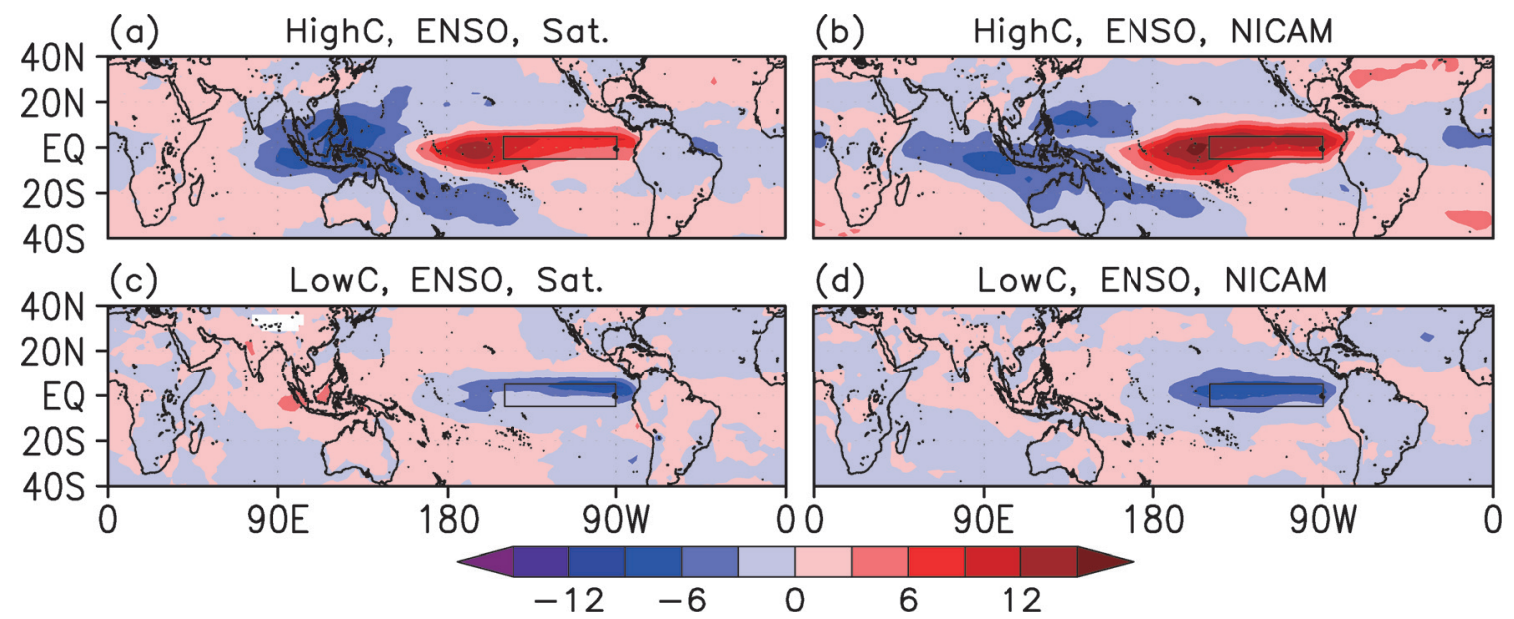

Fig. 5. Cloud amount response to ENSO during 1984-1998 for satellite (left) and NICAM (right) results. The monthly mean high (top) and low (bottom) cloud amounts in \% were regressed on ENSO index, respectively, and regression coefficients are shown.

bias is small despite the significant overestimation of high cloud amount. This may be attributable to an underestimation of middle cloud (as described next) as well as lower sensitivity of the LWCRF on high cloud amount in the extratropics compared with that in the tropics. Note that observed ISCCP polar cloud is highly uncertain (Rossow and Schiffer 1999), so the model bias is unclear there. Low and middle cloud amounts simulated by the model are significantly underestimated compared with observations, though their geographical distributions are qualitatively simulated. The underestimation is most prominent over the continent, near the west coast, and in storm track regions where the simulated negative SWCRF tends to be lower than observations (Fig. 3).

Compared with typical CMIP5 models (Wang and Su 2013), global mean OSR bias simulated by NICAM is more significant in association with the deficit in low and middle cloud amounts. In contrast to this study, Noda et al. (2010) showed that the low cloud amount was overly simulated in the extratropics using the previous version of NICAM. The sensitivity of cloud amount and radiation to the model configurations such as cloud microphysics scheme, horizontal and vertical resolutions, and several tuning parameters are being investigated intensively to improve the model's climate.

Figure 5 shows low and high cloud amount responses to ENSO. The interannual variability of high cloud amount due to ENSO resembles that of precipitation (Fig. 2). Both the observation and the model show more high cloud amount over the trop- ical central to eastern Pacific and less over the tropical western Pacific during the El Niño phase. The model simulates weaker negative anomaly of high cloud amount around the equatorial western Pacific compared with the observation. The basic characteristics of the ENSO-induced low cloud variability are also captured by the model; low cloud amount is decreased (increased) over the tropical central to eastern (western) Pacific due to ENSO. The simulated ENSO-induced low cloud variability is weaker in amplitude than the observation over the tropical western Pacific.

\subsection{Zonal mean basic states}

Figures 6 and 7 show the zonal mean temperature and zonal wind during JJA and DJF. Temperature and zonal wind structures, including seasonal and hemispheric differences, are simulated. Warm bias is found in the tropical upper troposphere compared to JRA-55 reanalysis (Table 1), i.e., simulated tropical static stability is greater. It is related to the excess of high cloud (Fig. 4, bottom) due to the treatment of cloud ice removal processes in cloud microphysics scheme (Seiki et al. 2015a). During JJA, warm bias is also found in the NH extratropical troposphere. The simulated tropospheric westerly jets (Fig. 7) are stronger and/or located more poleward relative to reanalysis results, part of which is associated with the lack of orographic gravity wave drag scheme in the simulation (McFarlane 1987). In the stratosphere, the simulated polar night jets are located more equatorward, and the easterly jets in the summer hemisphere are 


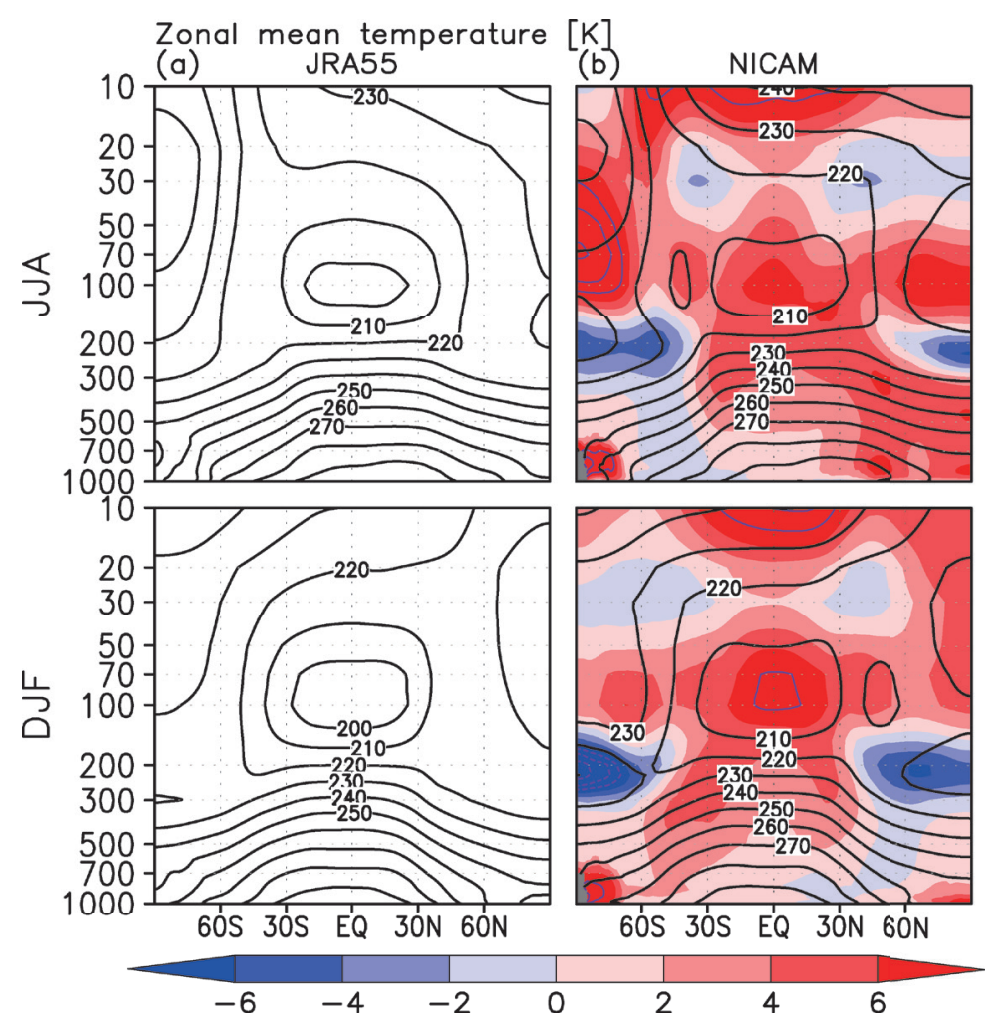

Fig. 6. Seasonal climatology of the zonal mean temperature in K for JRA-55 (a) and NICAM (b) results calculated during JJA (1979-1998) and DJF (1979/80-1998/99), respectively. The vertical axis shows pressure in hPa. Colored regions in (b) show anomalies from JRA-55. Anomaly exceeding $8 \mathrm{~K}$ is denoted as purple contour with an interval of $2 \mathrm{~K}$.

weaker than those in JRA-55.

Figure 8 shows Lagrangian-mean meridional circulations derived using mass-weighted isentropic zonal means (Iwasaki 1989). There are two major direct circulations: the Hadley circulation in the tropics and the extratropical circulation associated with baroclinic instability in the winter hemisphere. The simulated strength and width of the Hadley and extratropical circulations are comparable to JRA-55 results. During DJF (Fig. 8, bottom panels), the upwelling branch of the simulated Hadley circulation is located slightly southward, consistent with the zonal mean precipitation (Fig. 1). The Hadley circulation mass stream function has double extrema in JRA-55 results but a single extremum in NICAM results. Such differences seem to be within the range of uncertainties among reanalysis datasets. The strength and shape of the Hadley circulation strongly depend on reanalysis datasets (Nguyen et al. 2013; Iwasaki et al. 2009).

\subsection{Surface air temperature}

Figure 9 shows the surface air temperatures during JJA and DJF. The simulated global mean surface air temperature is higher than that in JRA- 55 by $0.72 \mathrm{~K}$ in JJA and $0.49 \mathrm{~K}$ in DJF. Such a warm bias mainly occurs over the continents, and is usually greater in summer than in winter. Significant warm bias is found over the Eurasian and North American continents in summer. The warm bias persists over the South American and South African continents, and is consistent with the under-simulated continental low and middle cloud amounts (Fig. 4) and the associated deficit in negative SWCRF (Fig. 3). With the exception of Greenland, the model simulates warmer arctic winter surface air temperatures (Fig. 9, bottom panels). SST drift from prescribed boundary conditions (Appendix A) causes ocean surface air temperature bias but by a smaller amount relative to the continental temperature bias. 


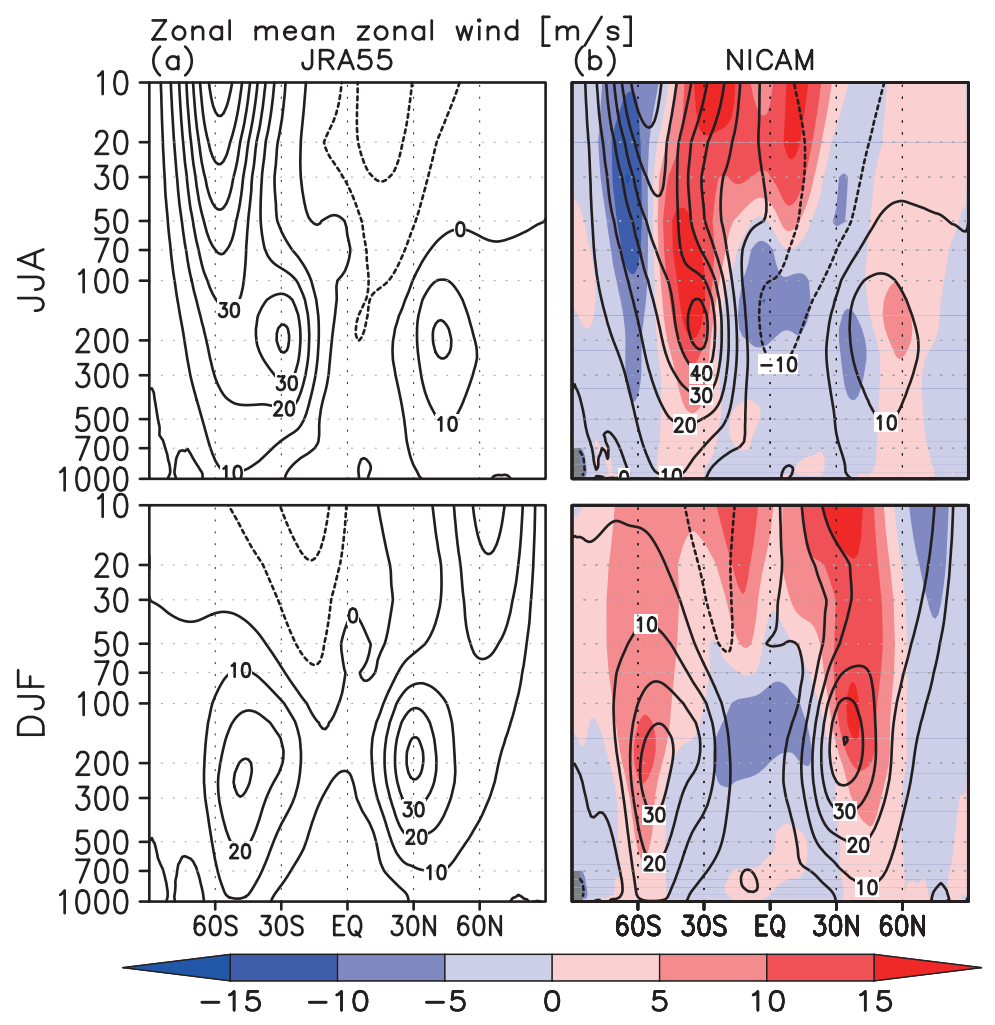

Fig. 7. Seasonal climatology of the zonal mean zonal wind in $\mathrm{m} \mathrm{s}^{-1}$ for JRA-55 (a) and NICAM (b) results calculated during JJA (1979-1998) and DJF (1979/80-1998/99), respectively. The vertical axis shows pressure in hPa. Colored regions in (b) show anomalies from JRA-55.

\section{Individual phenomena}

\subsection{Climatological tropical cyclone activity}

It is not easy for most climate models to adequately simulate the TC intensity and structure (Emanuel 2013). Though a climate model with a horizontal resolution of $O(100 \mathrm{~km})$ frequently reproduces geographical distributions and seasonal march of TCs, it tends to simulate much weaker than observed intensity and larger than observed size (Camargo 2013). Even 25-50 km mesh AGCMs cannot simulate intense (category 3-5) TCs despite the successful simulations of TC frequency (Zhao et al. 2009; Robert et al. 2015). In such cases, statistical downscaling approach (Zhao et al. 2010) may be useful to investigate the historical and future TC intensity. Recent studies have shown that AGCMs with a finer horizontal resolution, such as 10-20 km, reproduce more realistic TC intensity histograms (Murakami and Sugi 2010; Manganello et al. 2012; Manganello et al. 2014). However, the simulated TC intensity also strongly depends on the cumulus convection scheme (Murakami et al.
2012). As mentioned previously, no cumulus convection scheme was used in this study.

Here, TCs simulated by NICAM were analyzed as follows. First, TCs were directly detected using six-hourly mean-sea-level pressure data. They were then tracked following the method detailed by Sugi et al. (2002) and Oouchi et al. (2006) with a duration criterion of $36 \mathrm{~h}$. The maximum wind speed threshold of $17.5 \mathrm{~m} \mathrm{~s}^{-1}$ was objectively determined by the horizontal grid interval (Walsh et al. 2007). The TC detection and tracking algorithms and criteria do not depend on the ocean basin. We employed best track datasets produced by the National Hurricane Center (North Atlantic and eastern North Pacific; Jarvinen et al. 1984) and the Joint Typhoon Warning Center (western North Pacific, North Indian Ocean, and southern Hemisphere; Chu et al. 2002), and these datasets were unified in the IBTrACS (Table 1).

Figures $10 \mathrm{a}$ and $10 \mathrm{~b}$ show the geographical distributions of TC genesis. The TCs detected in the IBTrACS and NICAM per one year are approximately 82.4 and 81.8, respectively. Observed and simulated 


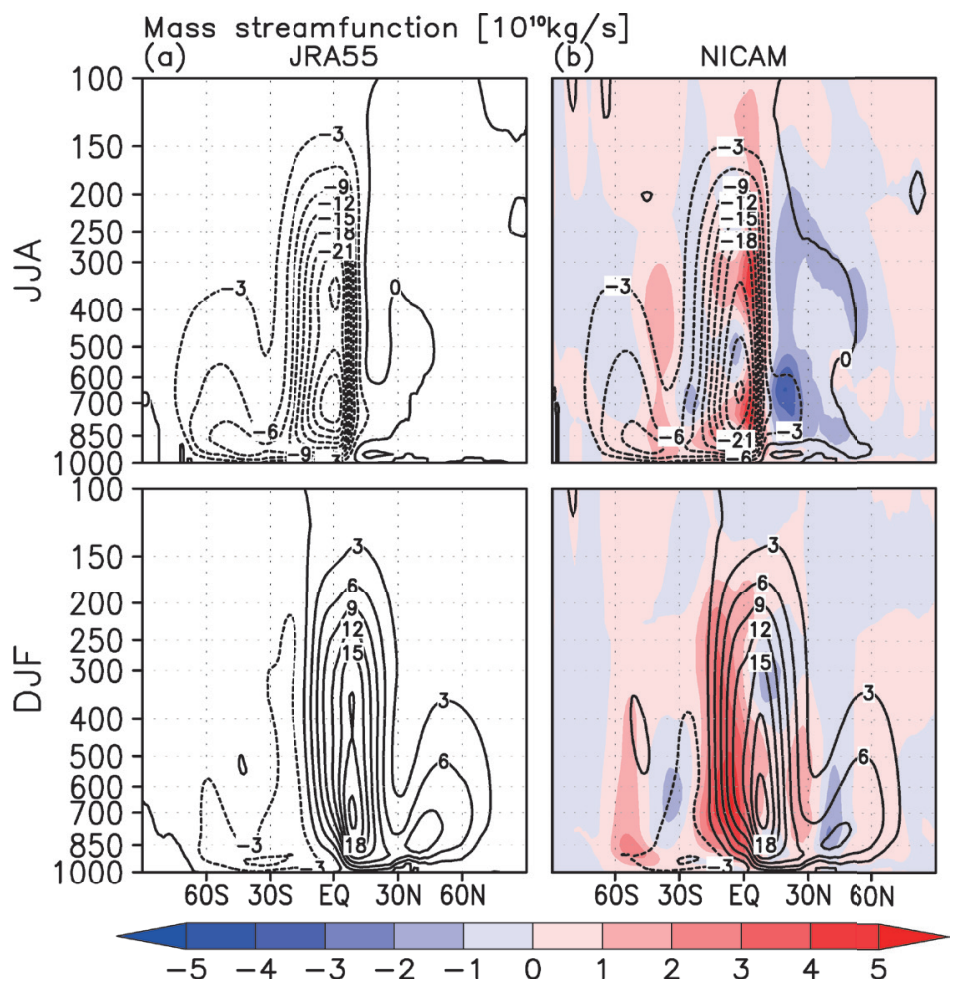

Fig. 8. Seasonal climatology of the zonal mean mass stream function in $10^{10} \mathrm{~kg} \mathrm{~s}^{-1}$ for JRA-55 (a) and NICAM (b) results calculated during JJA (1979-1998) and DJF (1979/80-1998/99), respectively. The vertical axis shows pressure in $\mathrm{hPa}$. Positive values indicate clockwise circulation.

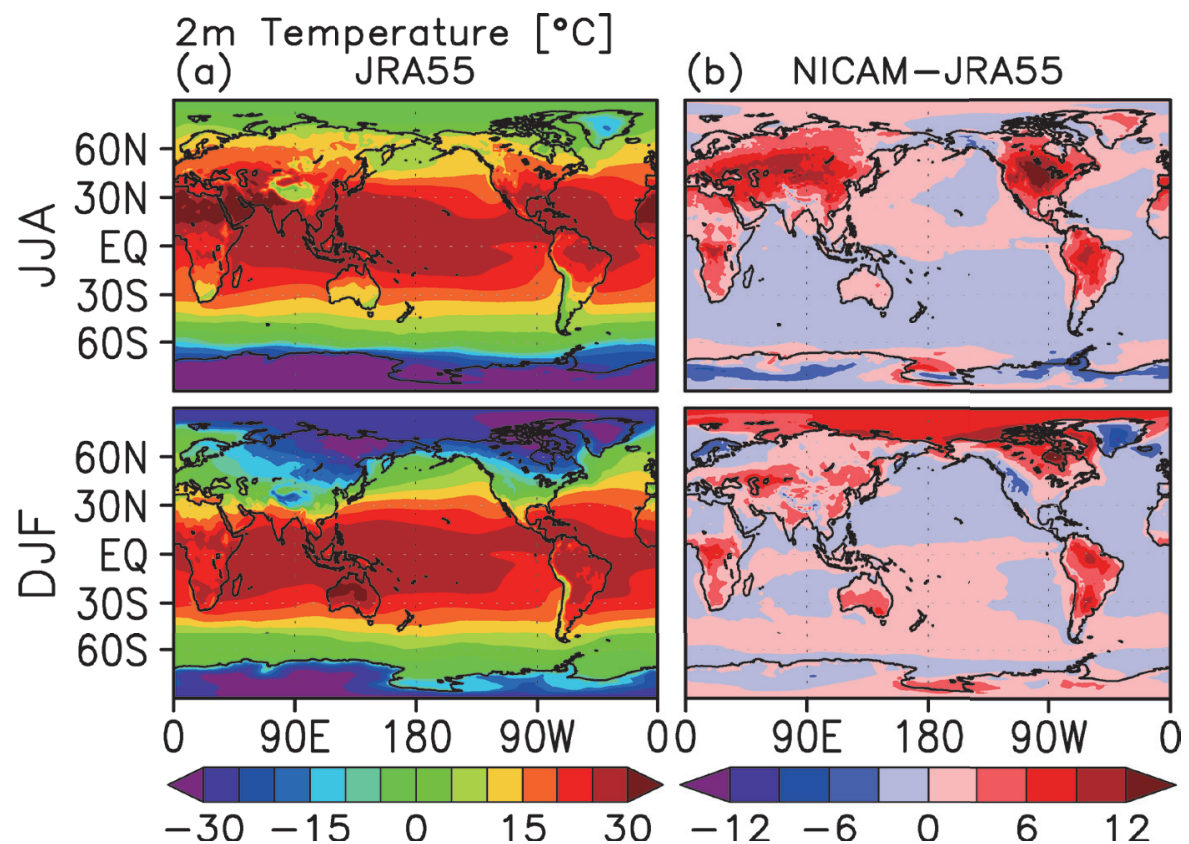

Fig. 9. Seasonal mean climatology of $2 \mathrm{~m}$ temperature in ${ }^{\circ} \mathrm{C}$ for JRA-55 (a) and NICAM - JRA-55 (b) calculated during JJA (1979-1998) and DJF (1979/80-1998/99), respectively. 
TC genesis density

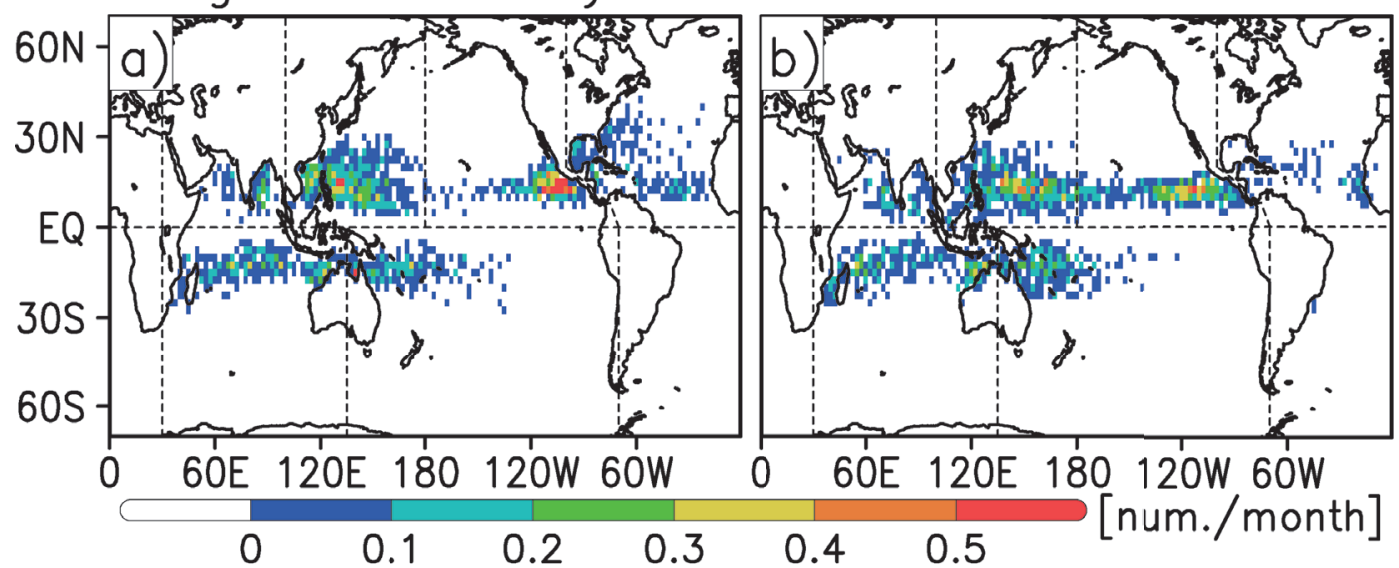

TC track density

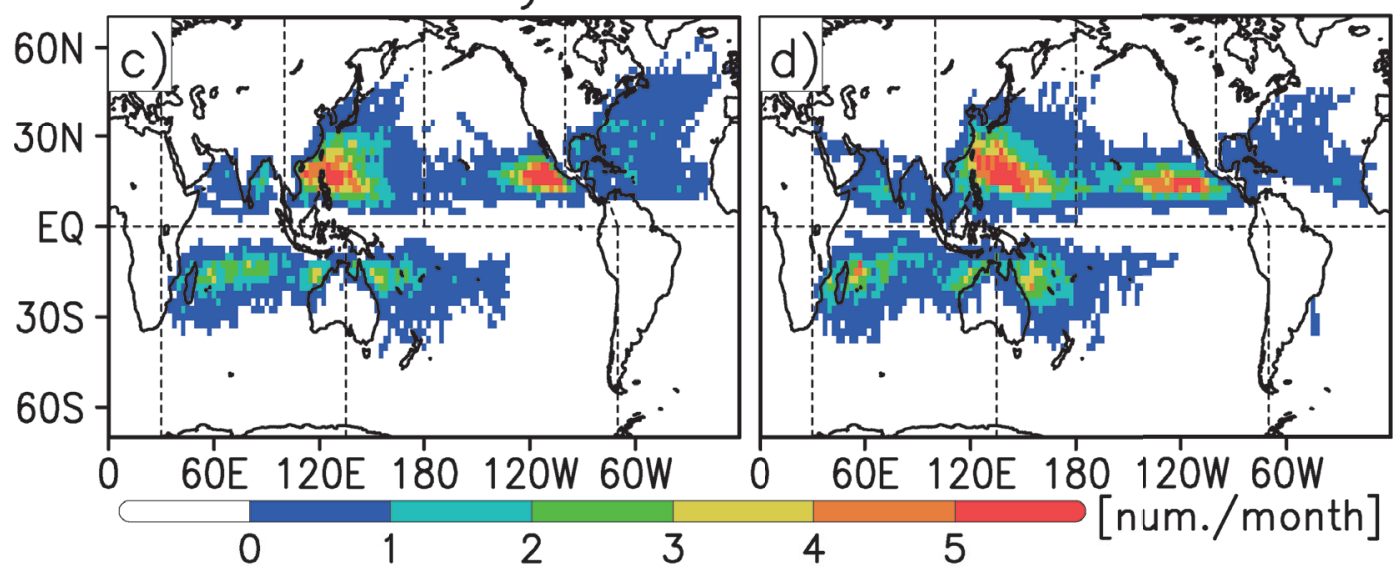

Mean TC intensity

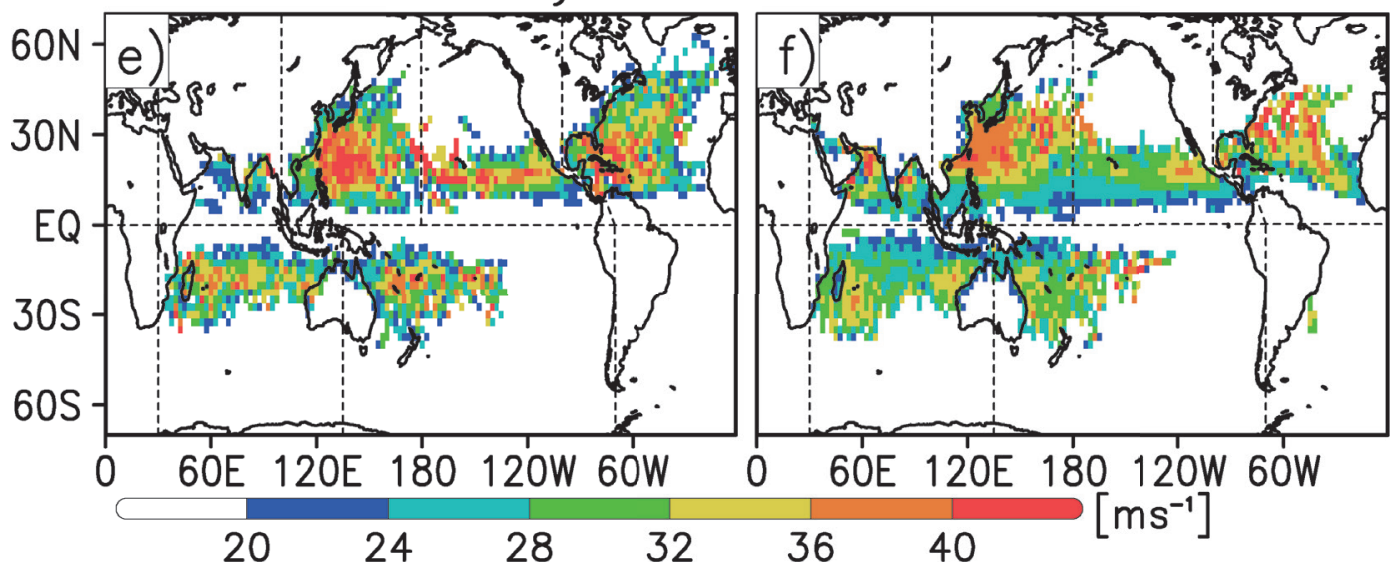

Fig. 10. Annual climatology of TC genesis density, TC track density, and mean TC intensity during 1979-1998. Observed values are shown in (a), (c), and (e), and NICAM simulations are shown in (b), (d), and (f). Dashed lines denote ocean basins. TC genesis and track density represent the number of TCs generated in and passing through each $2.5^{\circ} \times 2.5^{\circ}$ grid box per month. Mean TC intensity is defined as the maximum wind speed in $\mathrm{m} \mathrm{s}^{-1}$ averaged over all the TCs passing through each $2.5^{\circ} \times 2.5^{\circ}$ grid box. 
TC genesis distributions are usually similar. The number of TCs in both the IBTrACS and NICAM is in good agreement over the western North Pacific, Indian, and South Pacific oceans. However, NICAM produces less TCs over the North Atlantic Ocean and more from the eastern to central North Pacific Ocean. In addition, Figures $10 \mathrm{a}$ and $10 \mathrm{~b}$ show that the equatorward edge of the TC genesis region in the simulation is closer to the tropics than observation by a few degrees in latitude.

Figures 10c and 10d show the TC track density distribution. Over the Indian and South Pacific oceans, the TC track density is fairly well simulated. Over the western North Pacific Ocean, though the distributions of the TC track density are reasonably captured in the simulation, more TCs over the western North Pacific Ocean tend to move toward East Asia (from Taiwan to Japan) compared with the observations. The greater numbers of simulated TCs move westward across the date line in the North Pacific, consistent with high TC genesis in the central/eastern North Pacific region. Focusing on the North Indian Ocean, TC occurrences are less than observation over the Bay of Bengal and more over the Arabian Sea, which is similar to that in Zhao et al. (2009) and Murakami et al. (2012) but dissimilar to Manganello et al. (2012) and Roberts et al. (2015).

Figures $10 \mathrm{e}$ and $10 \mathrm{f}$ show the mean TC intensity. The simulated TC intensity, on average, is comparable to observations. As with genesis and track densities, the mean TC intensity over the South Pacific and South Indian oceans are relatively well simulated. Overall, the simulated mean TC intensity tends to be higher than the observations, especially in the higher latitudes. However, an exception is found in the central/eastern North Pacific Ocean, where, on average, a greater number of the simulated TCs tends to move westward.

Figure 11 shows the seasonal march of TC genesis in the six typical ocean basins. The number of simulated monthly TC genesis closely resembles observations in most ocean basins. Both the mean and magnitude of the interannual variations in monthly TC genesis are well reproduced in the simulation. Over the North Indian Ocean, the two observed local TC genesis maxima are captured by the model, but the timing of the simulated maximum in early summer is slightly earlier. Over the North Atlantic and eastern North Pacific, the model attempts to reproduce active and inactive TC seasons, though the seasonal cycle is shifted toward a later season.

NICAM captures the behaviors of TCs with objec- tively determined thresholds of maximum wind speed due to the intensity of simulated TCs. In particular, the reproducibility of the seasonal march of TC genesis is encouraging. TC biases are also found; few genesis in the North Atlantic, more moving from the eastern to the Central Pacific, and the delay of the seasonal cycle of TC genesis over the North Atlantic and eastern North Pacific. These may be related to the biases in basic fields, the use of the slab ocean model, cloud microphysics scheme configuration, horizontal resolution, etc. Serra et al. (2010) found that the strength of the Caribbean low-level jet is positively (negatively) correlated with the TC frequency over the eastern North Pacific (North Atlantic). Therefore, we speculate that the TC genesis biases over the North Atlantic and eastern North Pacific in the NICAM simulation are related to the stronger Caribbean low-level jet (not shown) associated with more active ITCZ convection (Fig. 1) over the tropical eastern North Pacific. Robert et al. (2015) recently found that the simulated TC track becomes more frequent over the Central Pacific as horizontal resolution is increased from 130 to $25 \mathrm{~km}$ (resolution at midlatitude). The lack of SST reduction by upwelling associated with strong surface winds, which seems to be favorable for maintaining TC intensity, may primarily contribute to the higher intensity bias in higher latitudes.

\subsection{MJO and convectively coupled equatorial waves}

This section addresses tropical intraseasonal (i.e., up to 90 days) variability with particular focus on two components: 30-90 day variability, often referred to as the MJO (Madden and Julian 1971, 1972) or as the tropical intraseasonal oscillation (ISO) and the other so-called convectively coupled equatorial waves (CCEWs) (Kiladis et al. 2009). Together they are responsible for a substantial portion of the tropical intraseasonal variability in various fields such as precipitation and winds.

Since the detailed analysis of the statistical behavior of ISOs will be addressed in another study (Kikuchi et al. in revision), we summarize the results. Kikuchi et al. (in revision) made a detailed assessment of the performance of NICAM in reproducing the ISOs in the context of the bimodal ISO representation concept proposed by Kikuchi et al. (2012). Many fundamental features of the ISOs such as the evolution of cloudiness patterns and seasonal cycles are relatively well reproduced, although the simulated ISOs are weaker in amplitude than observations by a factor of approximately 2 . We show the essen- 

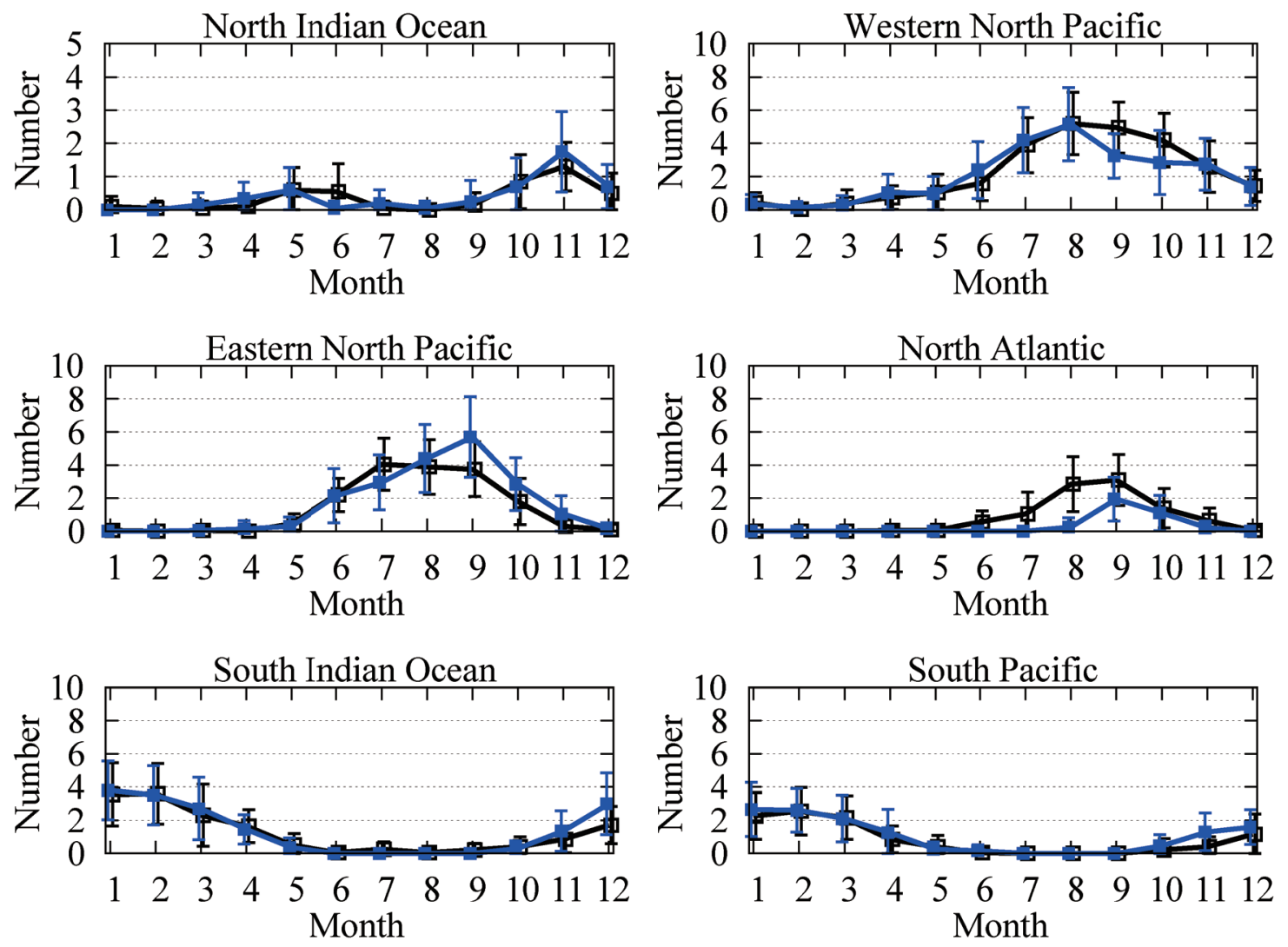

Fig. 11. Monthly mean climatological number of TC genesis and its standard deviation in each ocean basin defined in Fig. 10. IBTrACS results are shown in black, and NICAM results are shown in blue.

tial features of the simulated ISO in a simpler manner with the results that are consistent with Kikuchi et al. (in revision).

Figure 12 shows the time against longitude sections of a lagged correlation of 25-90 day OLR anomalies during boreal winter when eastward propagation is pronounced (Kikuchi et al. 2012; Kiladis et al. 2014). Although the simulated ISO amplitude is weaker by a factor of approximately 2 , which is in agreement with the results of Kikuchi et al. (in revision), NICAM reproduces the lifecycle of the ISO convection relatively well: maximum intensity over the central Indian Ocean, slowdown in phase speed to the east and west of the Maritime Continent, and weakening in amplitude over the Maritime Continent.

NICAM also captures the statistical properties of the CCEWs well. Figure 13 shows the normalized space-time power spectra. Here we followed the method developed by Wheeler and Kiladis (1999) to calculate the normalized spectra. The observation and simulation show significant spectral peaks along the dispersion curves corresponding to Matsuno's (1966) solutions of the shallow water equations on an equatorial beta plane with equivalent depths of $12-50 \mathrm{~m}$ (Kiladis et al. 2009), including Kelvin, equatorial Rossby, $n=1$ westward inertia-gravity, and mixedRossby gravity (MRG) waves and $n=0$ eastward inertia-gravity (EIG) waves. However, simulated MRG and $n=0$ EIG wave peaks are less significant, and their equivalent depths seem slightly deeper. The detailed analysis of the CCEWs will be conducted in future to explain the similarities and differences in spectral characteristics between the observations and NICAM simulation, especially from a nonstationarity viewpoint (Kikuchi 2014).

\subsection{Seasonal cycle of Asian summer monsoon}

Asian monsoon characterizes the seasonal cycle of the Indo-Pacific domain. The Asian monsoon is divided into several sub-systems, including Indian, western North Pacific, and East Asian monsoons such as Baiu (Section 4.4), and their stepwise seasonal 

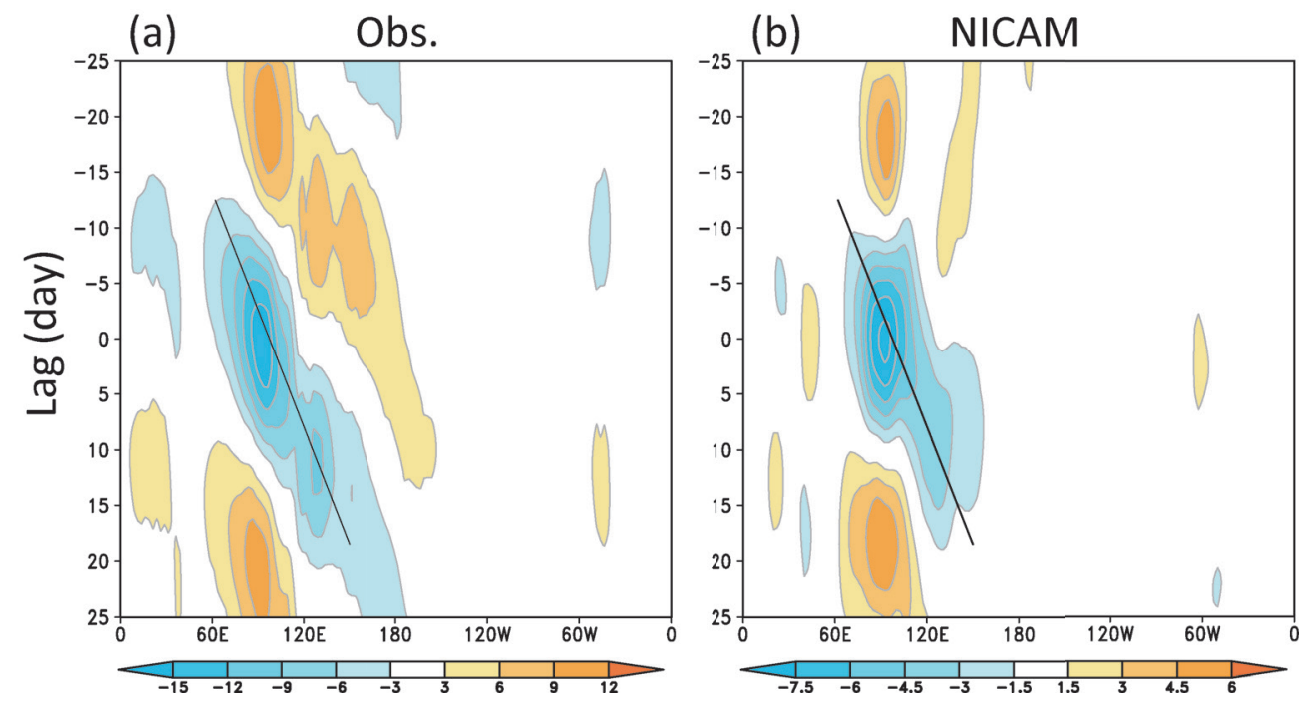

Fig. 12. Lagged regression of 25-90 day OLR anomalies averaged over $7.5^{\circ} \mathrm{S}$ and $7.5^{\circ} \mathrm{N}$ against $25-90$ day OLR anomalies over the equatorial Indian Ocean $\left(85-95^{\circ} \mathrm{E}, 5^{\circ} \mathrm{S}-5^{\circ} \mathrm{N}\right)$ during boreal winter (DJF). NOAA (Table 1) OLR values are shown in (a), and NICAM results are shown in (b). Note that the contour levels for (a) and (b) are different, as indicated in the color bars. The solid line represents a reference phase speed of approximately 3.6 $\mathrm{m} \mathrm{s}^{-1}$.

evolution and mutual connections have been intensively investigated (Murakami and Matsumoto 1994; Wang et al. 2001, 2004; Wang 2006). This section discusses the reproducibility of the climatology and interannual variation of the Asian summer monsoon. In particular, the monsoonal circulation over the western North Pacific, which is closely related to tropical cyclogenesis in summer (Holland, 1995; Ritchie and Holland 1999; Yoshida and Ishikawa 2013), is highlighted.

The Asian summer monsoon typically appears in the low-level wind fields as a response to the warming over the Eurasian continent. Figure 14 shows the June-September (JJAS) mean climatology of the 850 $\mathrm{hPa}$ wind field in the JRA-25 reanalysis (Table 1) and the NICAM simulation. Westerly winds over the tropical Indo-Pacific domain, connected to the Somali jet along the eastern coast of Africa extending to the Philippine Sea, is reproduced in the model (Figs. $14 a, b)$. The westerlies form part of a cyclonic circulation over the continent, and their simulated magnitudes along the peak axis are comparable to JRA-25 results. This is a significant improvement over the eight-year boreal summer hindcasts (Satoh et al. 2012), which used previous versions of NICAM with $7 \mathrm{~km}$ mesh; the monsoonal westerlies were poorly maintained in those cases. Model biases are also found in this study. For example, the northward displacement of the westerly axis occurs, which leads to easterly biases over the equatorial Indian Ocean, and the northwestern Pacific anti-cyclone is displaced northward with higher mean intensity (Fig. 14c). The biases of weaker westerlies over the equatorial Indian Ocean and a stronger North Pacific subtropical high (NPSH) were also detected in Coupled Model Intercomparison Project phase 5 (CMIP5) multimodel ensemble mean (Sperber et al. 2013). In the present simulation, the biases can be attributed to the warmer surface air temperature over the land during boreal summer (Fig. 9b). The northward error in the latitudes of the westerly axis leads to excessive Himalayan precipitation (Fig. 14c). The annual cycle of the western North Pacific Monsoon Index (WNPMI), defined by the meridional shear of zonal wind at 850 $\mathrm{hPa}$ averaged in the tropical $\left(100-130^{\circ} \mathrm{E}, 5-15^{\circ} \mathrm{N}\right)$ and subtropical $\left(110-140^{\circ} \mathrm{E}, 20-30^{\circ} \mathrm{E}\right)$ subdomains (Wang et al. 2001), is presented in Fig. 14d. The tropical subdomain includes the South China Sea (SCS), and the WNPMI corresponds to the convective activity over the SCS and Philippines with associated wind fields. The 20-year climatology of the annual cycle is reproduced in the simulation with a 0.83 correlation coefficient with JRA-25 results (Fig. $14 \mathrm{~d})$. Note that the climatological monsoon onset (i.e., WNPMI $>0$, followed by continuous positive values) in mid-June is well captured, as well as a sharp 

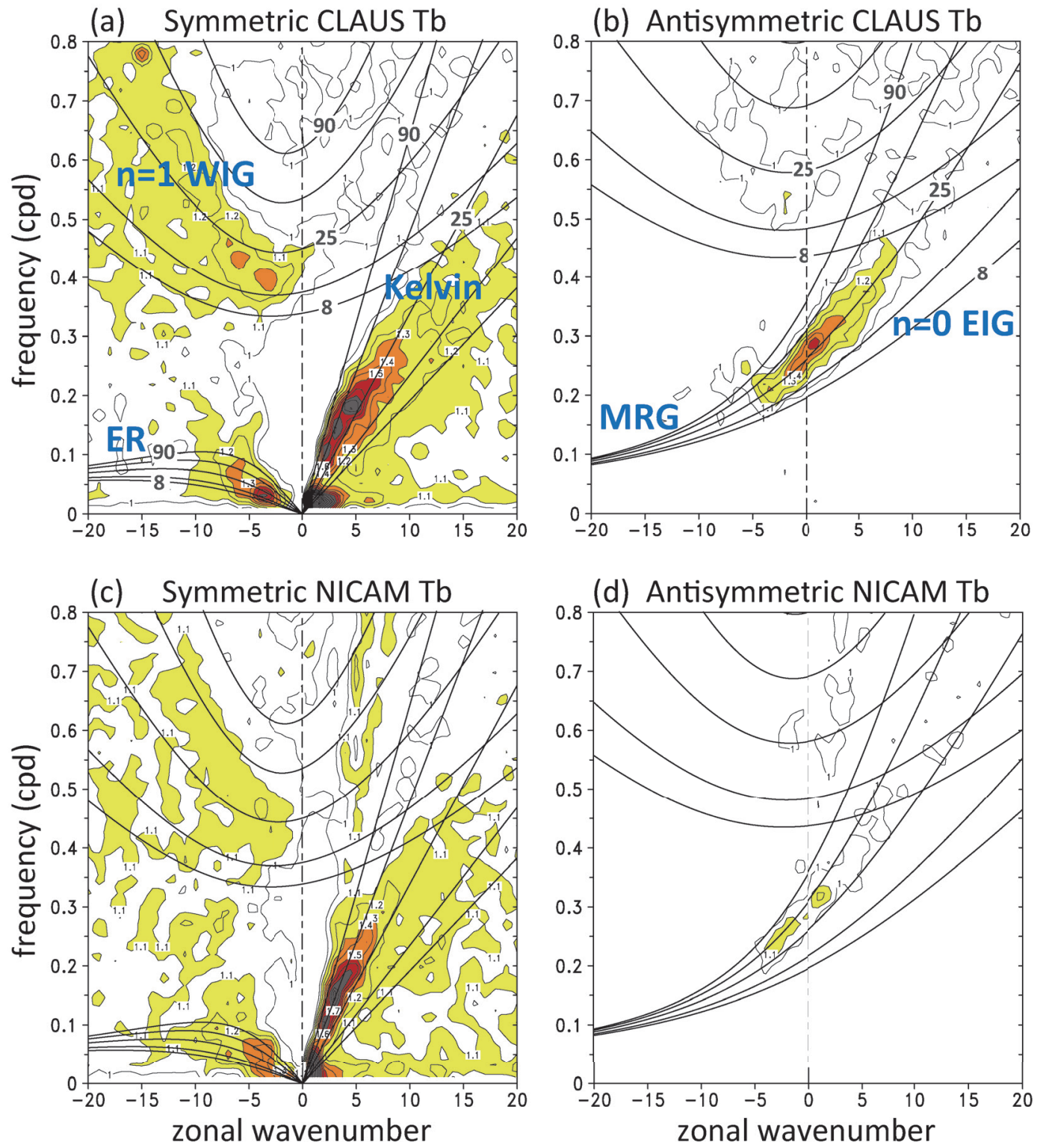

Fig. 13. Zonal wavenumber-frequency power spectrum estimates of CLAUS (Table 1) (top) and NICAM (bottom) brightness temperature ( $\mathrm{Tb}$ ). CLAUS results were calculated from July 1983 to June 2006, and NICAM results from 1979 to 1998 for the equatorially symmetric (left) and antisymmetric (right) components. Each spectrum was averaged between $15^{\circ} \mathrm{S}-15^{\circ} \mathrm{N}$ and normalized by a red noise background power spectrum. Solid lines denote dispersion curves for the Kelvin, $n=1$ equatorial Rossby, $n=1$ and $n=2$ westward inertia-gravity, $n=0$ eastward inertia-gravity, and mixed Rossby-gravity waves with equivalent depths of 8, 12, 25, 50, and $90 \mathrm{~m}$.

increase in the WNPMI in mid-May, followed by a tentative reduction for several weeks. The negative bias in the WNPMI during July-October is due to the northern displacement of the westerly axis (Fig. 14c).

The 20-year time series of the normalized WNPMI during boreal summer also shows general agreement between JRA-25 and NICAM results (Fig. 15a). Close examination finds that the interannual variation during the latter half of the analysis period is better reproduced than those in the former period. Such reproducibility difference does not correspond to the ENSO. Because the low-level circulation is closely associated 

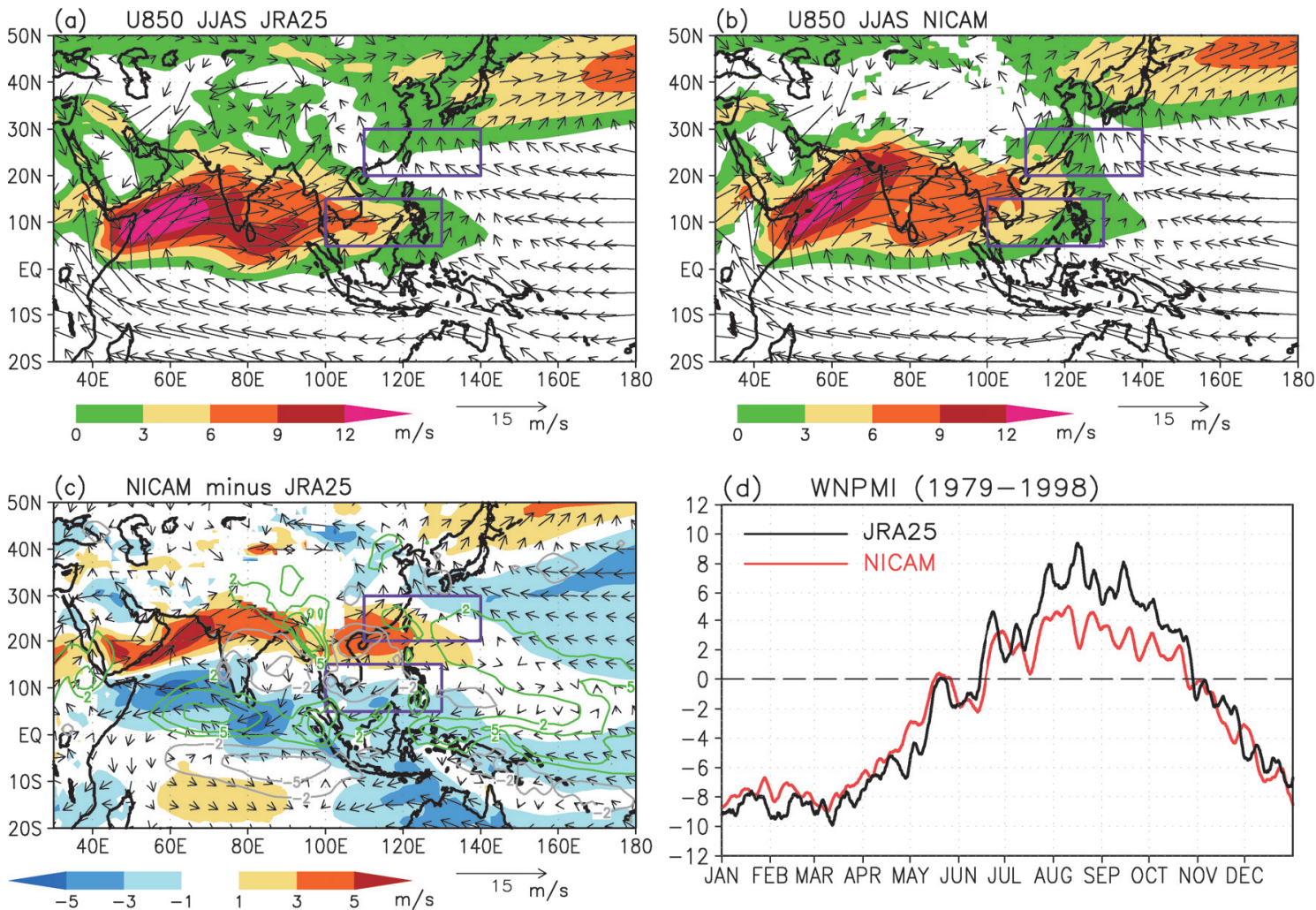

Fig. 14. $850 \mathrm{hPa}$ zonal wind and wind vectors for JRA-25 (a), NICAM (b), and NICAM - JRA-25 (c) results averaged during June-September (JJAS) (1979-1998). Colored regions represent the zonal wind, and arrows represent wind vectors. Colored outlines in (c) show NICAM - GPCP in precipitation rates with green representing 2, 5, and 10 and gray -2 and $-5 \mathrm{~mm}^{-1}$ day $^{-1}$. A time series of the western North Pacific Monsoon Index (WNPMI) (Wang et al. 2001) for JRA-25 (black) and NICAM (red) is shown in (d) using the 5-day running mean. Purple boxes in (a)(c) indicate WNPMI subdomains.

with convective activity, the interannual variations of observed and simulated OLR anomalies over the western North Pacific domain $\left(110-160^{\circ} \mathrm{E}, 0-25^{\circ} \mathrm{N}\right)$ were also examined (Fig. 15b). The time series of the WNPMI and OLR anomalies are negatively correlated (at a correlation coefficient of -0.67 in the observation and -0.65 in the model), and the WNPMI is better simulated when the OLR anomalies (Fig. 15b) are better reproduced. Lau et al. (1997) argued that the anomalous convection in the tropics is related to large-scale circulation rather than local SST on interannual timescales. Further model evaluation of the basin-scale SST anomalies and convective responses, including the remote effects, is warranted to improve the model performance.

\subsection{Baiu front as a boundary between the tropics and mid-latitudes}

The Baiu front (BF) is a part of the large-scale
Asian summer monsoon (Murakami and Matsumoto 1994; Wang and LinHo 2002). It stays near Japan during June and July, and sometimes causes serious natural disasters such as drought or torrential rain in East Asia. The BF is defined as a boundary between the air masses of the tropics and mid-latitudes and is suitable to evaluate the dynamical and thermodynamical performance of NICAM at the edge of the tropics. This section identifies the differences in the spatial patterns (Fig. 16) and the time progress (Fig. 17) of the BF between objective analysis data (JRA-25, GPCP) and NICAM.

The air masses are classified by temperature and humidity. Therefore, this study used the lower tropospheric $(925-700 \mathrm{hPa})$ equivalent potential temperature $(<\theta e>)$, which was estimated using temperature as well as humidity. The meridional gradient of $<\theta e>(-\partial<\theta e>/ \partial y)$ was then employed to detect the boundary of the air masses, i.e., the BF. A $330 \mathrm{~K}<\theta e>$ 

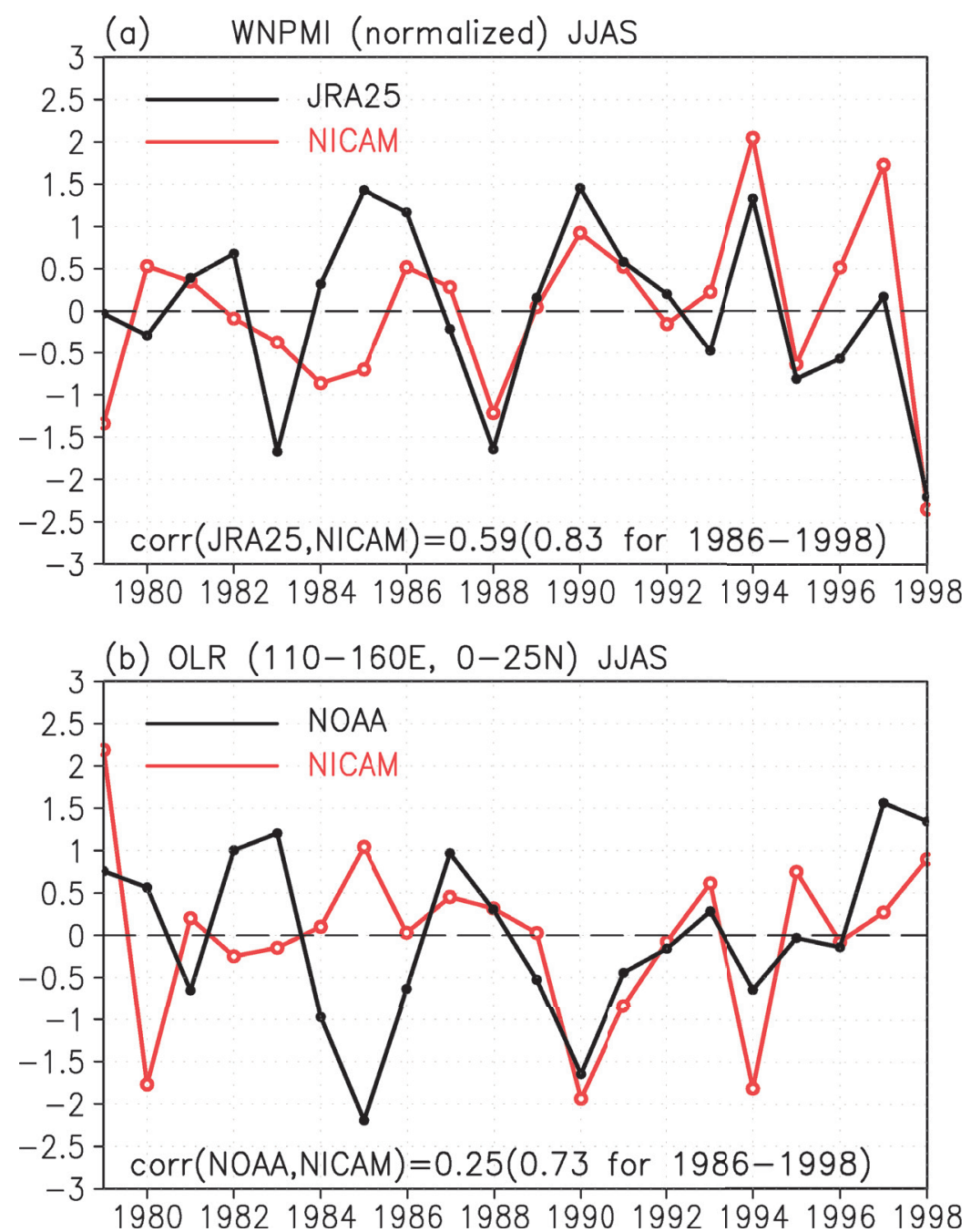

Fig. 15. Interannual variations of WNPMI (a) and OLR (b) averaged during JJAS normalized by the variances of each time series. JRA-25 (black) and NICAM (red) values are shown in (a). NOAA (Table 1) (black) and NICAM (red) values, calculated between $110-160^{\circ} \mathrm{E}$ and $0-25^{\circ} \mathrm{N}$, are shown in (b).

contour was also used to determine the boundary between the tropical and mid-latitude air masses in the East Asia (EA)-western North Pacific (WNP) sector (Saito 1966), although this position is different from the BF estimated using $-\partial<\theta e>/ \partial y$ (Fig. 16a). See Tomita et al. (2011) for the methodology details used in this section.

Figure 16 exhibits the climatological mean fields of $\langle\theta e>$ and $-\partial<\theta e>/ \partial y$ (upper panels) and precipitation and vertically integrated water vapor flux (lower panels) during the Baiu season near Japan (May 31July 29). The period of which was estimated based on the GPCP data. It is known that the precipitation corresponds with the convergence of the vertically integrated water vapor flux (Chen et al. 2012). In the fields of $\langle\theta e>$ and $-\partial<\theta e>/ \partial y$, the climatological BF in JRA-25 extends along the latitudes of Japan in the EA-WNP sector (Fig. 16a), while it is weak and has already reached near $40^{\circ} \mathrm{N}$ in NICAM (Fig. $16 \mathrm{~b}$, thick solid line). In this period, the monsoon air mass (MoAM) and heating in East Asia are stronger in NICAM than in JRA-25. In particular, $\langle\theta e\rangle$ is high in the zonal band between $40^{\circ} \mathrm{N}$ and $50^{\circ} \mathrm{N}$ in the EA-WNP sector (Fig. 16c), which seems to be related to the northward displacement and stronger intensity of the westerly winds over the EA-WNP sector, as mentioned in Section 4.3. The higher $\langle\theta e\rangle$ in this zonal band makes the BF weaker and the latitude 
(a) JRA-25: EPT

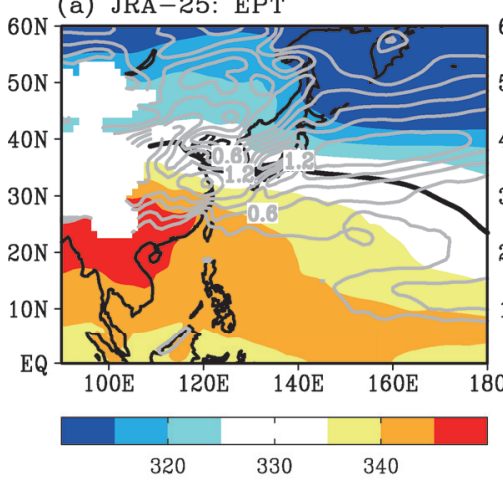

(b) NICAM: EPT
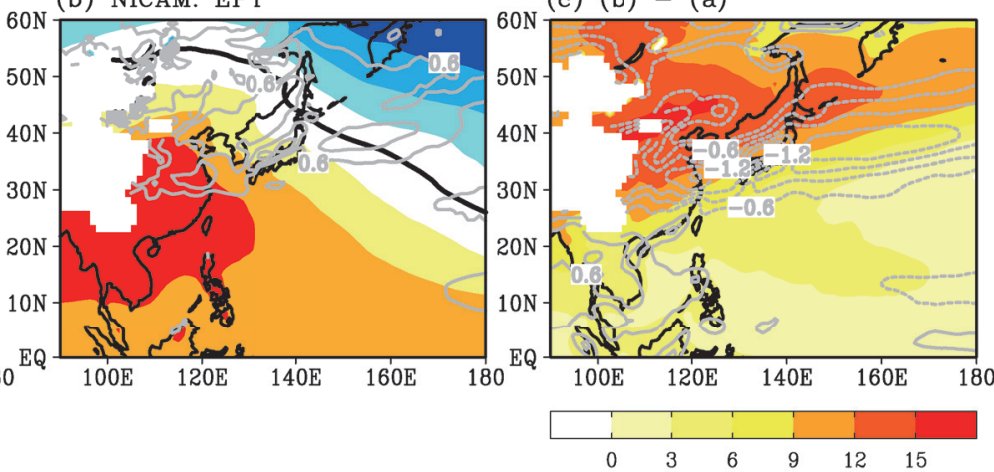

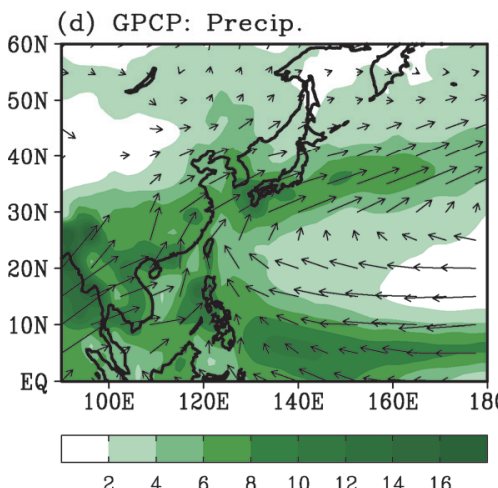

(e) NICAM: Precip.
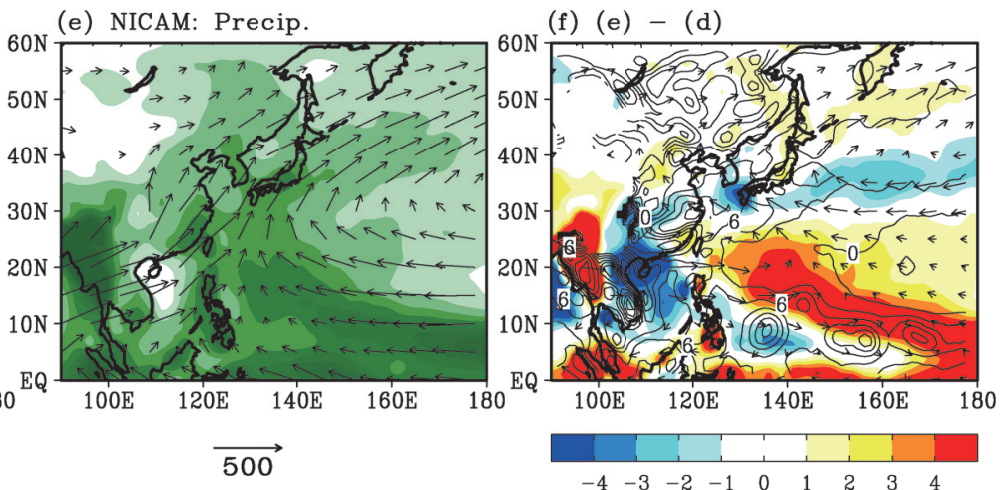

Fig. 16. Climatological (1979-1998; 20 years) mean fields of lower tropospheric (925-700 hPa) equivalent potential temperature $(\langle\theta e\rangle)$ and $-\partial<\theta e>/ \partial y$ in $\mathrm{K}$ and $10^{-5} \mathrm{~K} \mathrm{~m}^{-1}$ respectively, averaged during the Baiu season near Japan (May 31-July 29) for (a) JRA-25, (b) NICAM, and (c) NICAM - JRA-25. Colored regions indicate $<\theta e>$, and gray contours indicate $-\partial<\theta e>/ \partial y$. The contour interval is $0.3 \times 10^{-5} \mathrm{~K} \mathrm{~m}^{-1}$. In (a) and (b), only regions larger than $0.3 \times 10^{-5} \mathrm{~K} \mathrm{~m}^{-1}$ are contoured, while dotted contours in (c) identify the regions with a negative $-\partial<\theta e>/ \partial y$. A thick solid line is drawn on the $330 \mathrm{~K}\langle\theta e>$ in (a) and (b). In the lower panels, the corresponding climatological mean fields of precipitation $\left(\mathrm{mm} \mathrm{day}^{-1}\right)$ and vertically integrated $(300-1000 \mathrm{hPa})$ water vapor flux $\left(\mathrm{kg} \mathrm{m}^{-1}\right.$ $\mathrm{s}^{-1}$ ) are shown for (d) GPCP and (e) NICAM. The differences ((e) - (d)) are shown in (f), where the divergence of water vapor flux $\left(10^{-5} \mathrm{~kg} \mathrm{~m}^{-2} \mathrm{~s}^{-1}\right)$ is also depicted by contours. The colored regions show precipitation, and the vectors show the vertically integrated water vapor flux. The scale vector is placed at the bottom center.

higher. We also found higher $\left\langle\theta e>\right.$ along $20^{\circ} \mathrm{N}$ in the WNP in NICAM (Fig. 16c).

The corresponding precipitation fields (Figs. 16d-f) support the above results in $\langle\theta e\rangle$ and $-\partial<\theta e\rangle / \partial y$ (Figs. 16a-c). Even larger precipitation is observed along $20^{\circ} \mathrm{N}$ in the WNP in NICAM (Fig. 16e), which indicates that the WNP summer monsoon (WNPSM) leading the end of Baiu season (Tomita et al. 2011) has already started during this period. The vectors of water vapor flux also demonstrate the northward expansion of NPSH in NICAM (Fig. 16e). The differences (Fig. 16c) show that the Baiu season near Japan has already ended in May 31-July 29 in NICAM with the onset of WNPSM, the northward expansion of NPSH, and the northward shift of the BF. The diver- gence in water vapor flux is strong in NICAM in the EA-WNP sector (Fig. 16f). In the following, we will examine the temporal development of the $\mathrm{BF}$ in the objective analysis data and NICAM.

Figure 17 shows the differences in the northward movement of the BF near Japan $(-\partial<\theta e>/ \partial y$ averaged over $125-145^{\circ} \mathrm{E}$ ), which determines the beginning and ending of the Japanese Baiu season. The beginning occurs when the BF reaches $30^{\circ} \mathrm{N}$, and the ending occurs when it reaches $40^{\circ} \mathrm{N}$, which correspond to June 2 and July 31, respectively, in the JRA-25 reanalysis (Fig. 17a; Tomita et al. 2011). During this period, the relatively fast northward advance occurs in June in the JRA-25 reanalysis, while the speed slows in July. At the end of July, the 

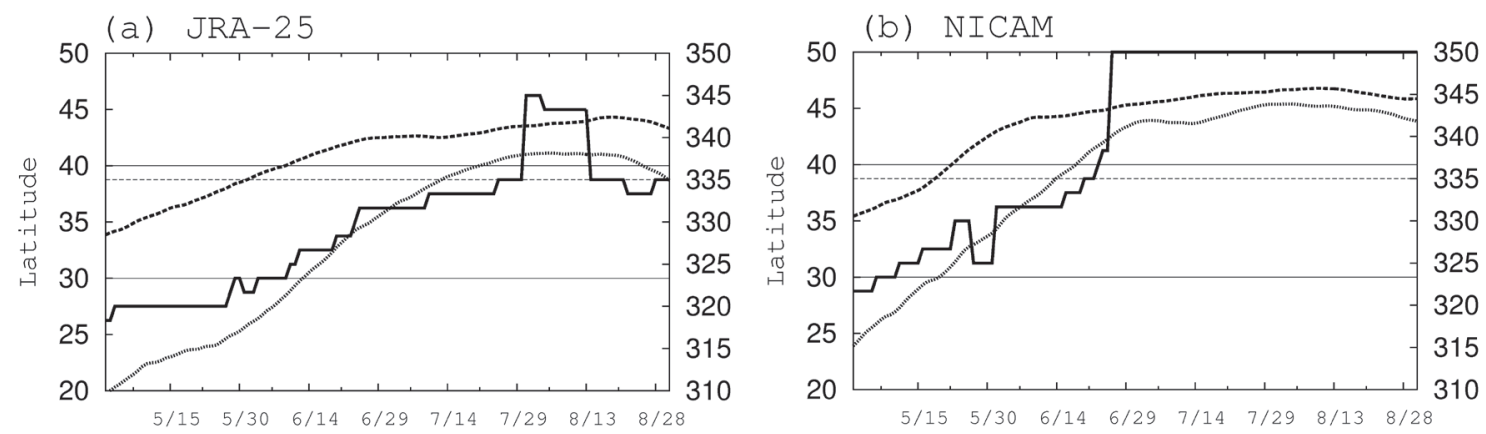

Fig. 17. Climatological mean time series of maximum $-\partial<\theta e>/ \partial y$ latitude averaged between $125^{\circ} \mathrm{E}$ and $145^{\circ} \mathrm{E}$ (stepwise solid line; left axis), $\angle \theta e>$ averaged from $125^{\circ} \mathrm{E}$ to $145^{\circ} \mathrm{E}$ and $30^{\circ} \mathrm{N}$ to $40^{\circ} \mathrm{N}$ (smoothed dotted line; right axis), and $\langle\theta e\rangle$ averaged from $125^{\circ} \mathrm{E}$ to $145^{\circ} \mathrm{E}$ and $20^{\circ} \mathrm{N}$ to $30^{\circ} \mathrm{N}$ (smoothed dashed line; right axis). JRA-25 results are shown in (a), and NICAM results in (b). Left axis shows maximum $-\partial<\theta e>/ \partial y$ latitude in degrees north, and the $30^{\circ} \mathrm{N}$ and $40^{\circ} \mathrm{N}$ latitudes are indicated as horizontal solid lines. Right axis shows $\langle\theta e\rangle$ in $\mathrm{K}$, and the $335 \mathrm{~K}\langle\theta e>$ is indicated as the horizontal dashed line.

$\mathrm{BF}$ advances to $45^{\circ} \mathrm{N}$, which marks the end of the Japanese Baiu season.

The NICAM climatological BF progresses northward much faster during the earlier and shorter period from early May to the end of June (Fig. 17b) compared with the JRA-25 BF. This seems to be caused by the faster and stronger northward expansion of the MoAM (Figs. 16a, b) and stronger surface heating in the eastern part of the Asian continent (Fig. 16c). Note that time progression pattern in NICAM (Fig. 17b) and JRA-25 (Fig. 17a) is slightly similar. In particular, the rapid northward advance occurs in the early period, then the BF remains near $35^{\circ} \mathrm{N}$ later in the period, and then finally jumps and passes $50^{\circ} \mathrm{N}$ at the end of the period. Thus, the correction of the MoAM northern expansion in East Asia and of the faster and stronger higher latitude heating over the Asian continent could improve the NICAM BF reproduction.

\subsection{Diurnal precipitation cycle}

This section summarizes the climatological diurnal precipitation cycle over the Southeast Asian monsoon region, the Maritime Continent, and the Central America during boreal summer. The diurnal precipitation cycle simulation over the Maritime Continent and Asian monsoon regions was difficult when a GCM with a cumulus convection scheme (Dai and Trenberth 2004; Dai 2006; Hara et al. 2009; Love et al. 2011) was used. Previous studies suggested that NICAM has an advantage in reproducing diurnal precipitation cycles (Sato et al. 2009; Dirmeyer et al. 2011; Noda et al. 2012). Sato et al. (2009) performed
NICAM for one month with 14,7 , and $3.5 \mathrm{~km}$ resolution meshes and showed that the diurnal peak in precipitation becomes more realistic over land as the horizontal resolution increases. Dirmeyer et al. (2011) showed that high resolution models including updated NICAM have simulated nocturnal precipitation over a continent, for example, precipitations along the southern slope of the Tibetan Plateau. However, even in their project, the reproducibility of the nocturnal precipitations over the Southeast Asian monsoon region and the Maritime Continent is still a challenging issue. As we have seen, simulated precipitation climatology is improved, which can also improve the nocturnal precipitations. In addition, the analysis of the characteristic nocturnal precipitation over Central America, which propagates offshore, offers a good example to examine how "20-year" experiment improves diurnal precipitation signals. Though diurnal precipitation cycle over the Central America was simulated in the NICAM monthly and season-scale experiments (Sato et al. 2009; Noda et al. 2012), its signal-to-noise ratio seems to be weak, possibly due to its shorter analysis period.

The diurnal precipitation cycle is well simulated in the NICAM climate simulation (Fig. 18). The diurnal precipitation signals around the Tibetan Plateau, Southern China, and North America (not shown) were simulated, which was similar to the previous studies (Dirmeyer et al. 2011). Note that the simulated diurnal peaks in precipitation correspond to those observed by the TRMM-PR (Table 1) over the Asian monsoon and Maritime Continent regions (Fig. 18, left). Early morning precipitation is well simulated west of the 
(a) Diurnal Peak in Precip(TRMM-PR)

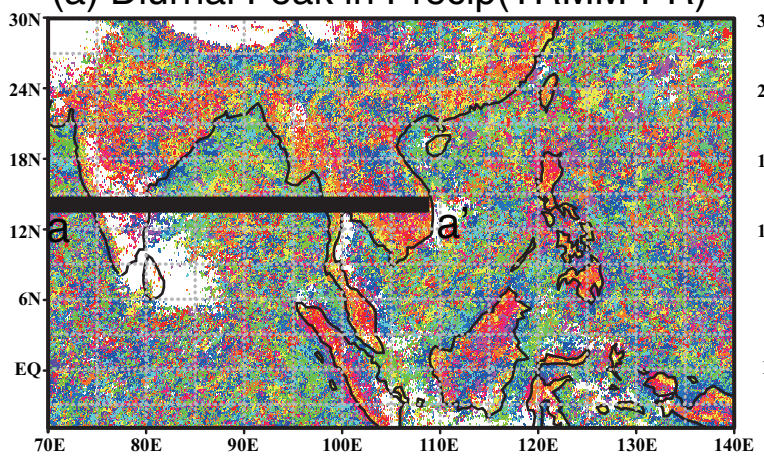

(c) Diurnal Peak in Precip(NICAM)

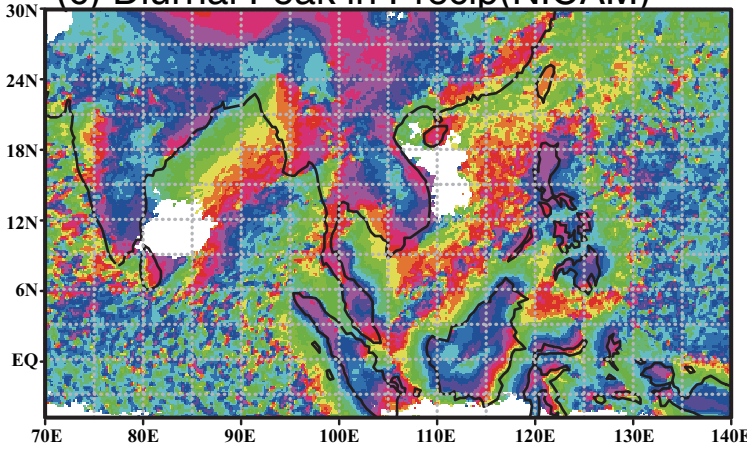

(b) Diurnal Peak in Precip(TRMM-PR)

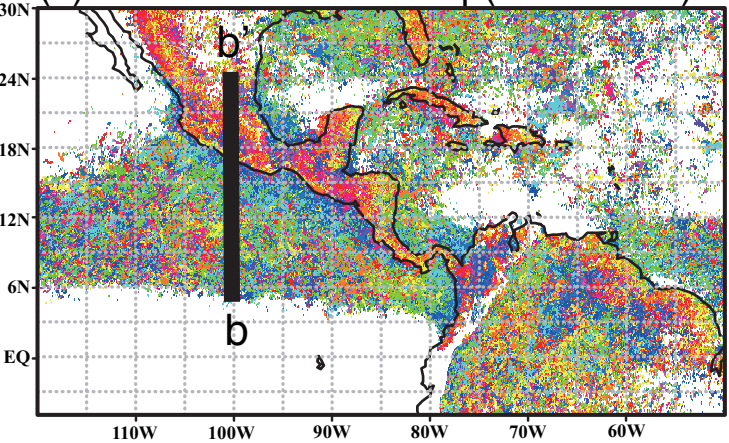

(d) Diurnal Peak in Precip(NICAM)

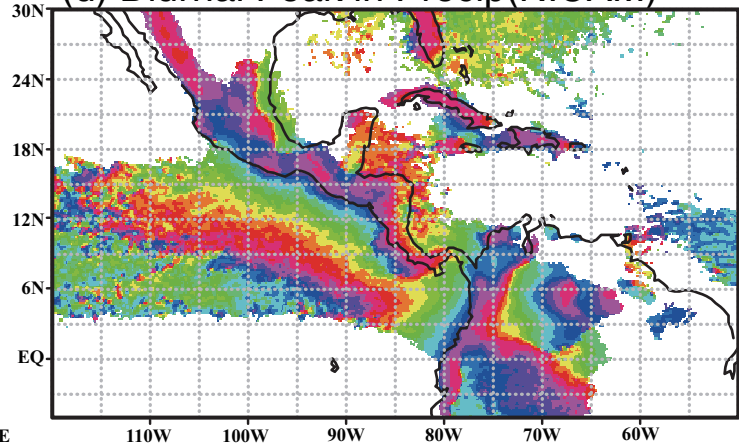

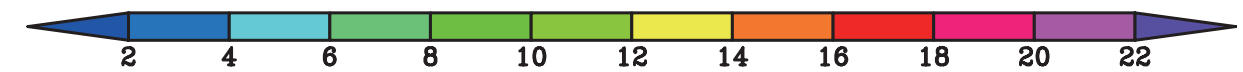
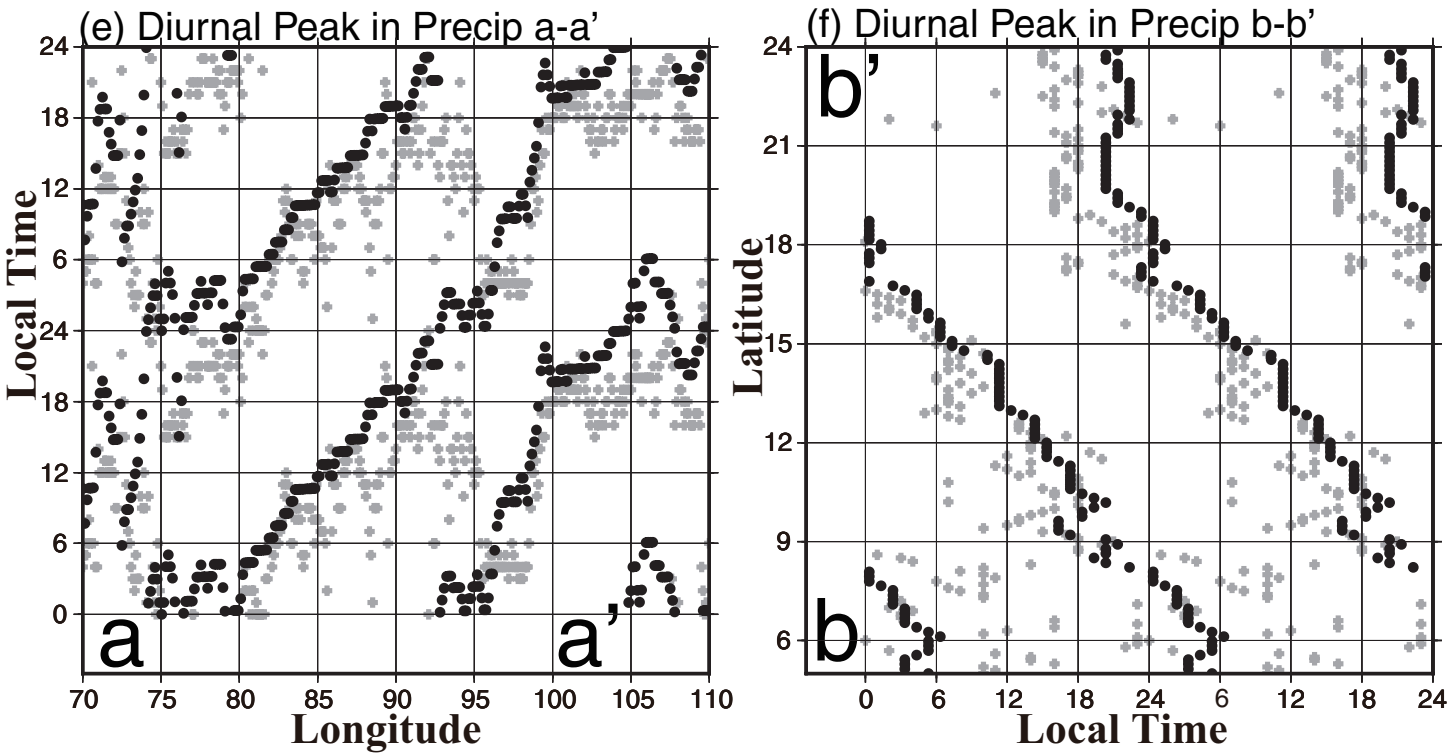

Fig. 18. Local time of climatological diurnal peaks in precipitation during JJAS in h. Longitude-latitude plots of the TRMM-PR observations between 1998 and 2012 (top) and NICAM simulations between 1979 and 1998 (middle) are shown for Asian monsoon and Maritime Continent (left) and Central America (right) regions. A diurnal peak in precipitation is defined as the first harmonic of the diurnal precipitation cycle in each grid box. Diurnal peaks in precipitation along the line a-a' in (a) and along the line b-b' in (b) are shown in (e) and (f), respectively, with black circles indicating simulated results and gray symbols indicating TRMM-PR observations. Horizontal and vertical axes in (e) are longitude and local time (repeated for 2 days), respectively, and those in (f) are local time and latitude. 
Indochina Peninsula and over the interior of Indochina Peninsula (Satomura 2000; Takahashi et al. 2010) and Borneo Island. In addition, diurnal precipitation systems, which propagate from coastal regions toward the ocean, are in good agreement with the TRMM-PR observations over the Bay of Bengal (Fig. 18 , left). The simulated nocturnal precipitation propagating offshore over the western coast of Central America (Fig. 18, right) is more systematic compared with the previous monthly and seasonal-scale simulations (Sato et al. 2009; Noda et al. 2012). The increase in the simulation period improves the diurnal precipitation signals over this region. The improvement in diurnal precipitation cycles, especially over the Southeast Asian monsoon region, can be associated with the improvements in the reproduction of mean climatological features such as monsoon westerlies and precipitation (Sections 4.3 and 3.1, respectively). Similar to the previous studies (Sato et al. 2009; Noda et al. 2012), the simulated diurnal peaks in precipitation are delayed by $2-4 \mathrm{~h}$ compared with the observations, especially over land. These systematic biases may be attributable to a poor representation of the vertical moisture transport at the lower atmosphere associated with the coarse horizontal resolution (Petch et al. 2002; Mass et al. 2002).

Fujita et al. (2011) analyzed the observational datasets and NICAM output and found a prominent diurnal convection cycle over the Indian Ocean during the MJO phases 2 and 3. As we have shown in Section 4.2 and here, NICAM simulates realistic climatology for the MJO as well as diurnal precipitation cycles, and thus is favorable for investigating their interaction.

\subsection{Lower stratospheric variability}

The importance of the troposphere-stratosphere coupling has been recognized because stratospheric variability is closely linked with tropospheric weather and climate (Baldwin and Dunkerton 2001). In this section, we demonstrate the stratospheric variability in monthly mean zonal-mean zonal wind in the NICAM simulation. Figures $19 \mathrm{a}$ and $19 \mathrm{~b}$ show the 30 $\mathrm{hPa}$ zonal wind frequency power spectra as a function of latitude for ERA-I reanalysis (Table 1) and NICAM simulation. NICAM simulates the annual and semiannual variability with its maximum values and latitudinal positions. In addition, variability over 7-11 months, as well as interannual variability, resembles ERA-I results.

Figures $19 \mathrm{c}$ and 19d illustrate the time-latitude cross-sections of interannual anomaly of the 30
$\mathrm{hPa}$ zonal wind. To extract interannual variability, the mean seasonal cycle (i.e., annual cycle) was calculated using data from 1979 to 1998 , and then subtracted from the raw data. The resulting time series were then smoothed using five-month running means (Kawatani and Hamilton 2013). The irregular occurrence of strong easterly/westerly anomalies near $60^{\circ} \mathrm{N}$ and $70^{\circ} \mathrm{S}$ are found in both the ERA-I reanalysis and NICAM simulation, although the phases of these anomalies are slightly different. The latitude-height distributions of interannual variability in NICAM are normally comparable with those in the ERA-I (not shown) in the mid- to high-latitudes, despite slightly weaker variability.

The most prominent interannual variability in the equatorial stratosphere is the quasi-biennial oscillation (QBO). Most comprehensive global models do not simulate this feature well (Kawatani and Hamilton 2013). Since the QBO is driven by interactions among the mean zonal wind and vertically propagating internal waves generated in the tropical troposphere (Baldwin et al. 2001), high horizontal and vertical resolution and appropriate representation of tropical convective variations are required to adequately simulate the QBO (Kawatani et al. 2009, 2010).

In the ERA-I data, large spectrum peaks are found 20-40 months in the tropical regions (Fig. 19a), and zonal winds change from strong easterlies to westerlies with a mean period of approximately 28 months (Fig. 19c). This QBO signal does not appear in the present NICAM simulation (Figs. 19b, d), possibly due to the coarse vertical resolution (i.e., approximately $2 \mathrm{~km}$ around $30 \mathrm{hPa}$ ). However, NICAM attempts to simulate the westerly/easterly changes in the tropical stratosphere despite much smaller amplitude. As shown in Fig. 13, NICAM succeeds in simulating CCEWs. Kawatani et al. $(2009,2010)$ demonstrated that CCEWs are the main source of equatorial waves with less than $90 \mathrm{~m}$ equivalent depths, which propagate from the troposphere into stratosphere. These equatorial waves comprise up to $50 \%$ of the force driving the westerly phase of the QBO. These results reveal that NICAM has the potential to adequately simulate the QBO with additional stratospheric vertical layers, and that it would be beneficial to further investigate troposphere-stratosphere coupling processes.

\section{Discussion}

Some of the biases found in this study seem to be common among most climate models. The doubleITCZ is still a problem in the NICAM simulation, 
(a) Power Spectra U 30hPa ERA-I

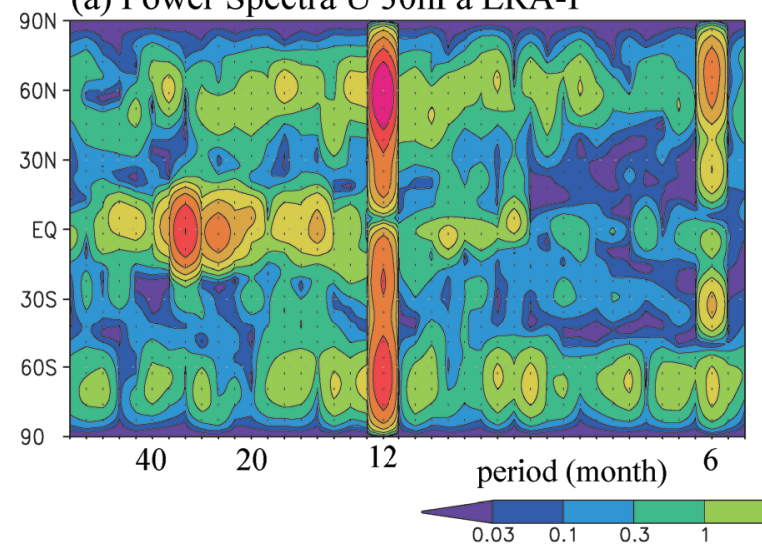

(b) Power Spectra U 30hPa NICAM

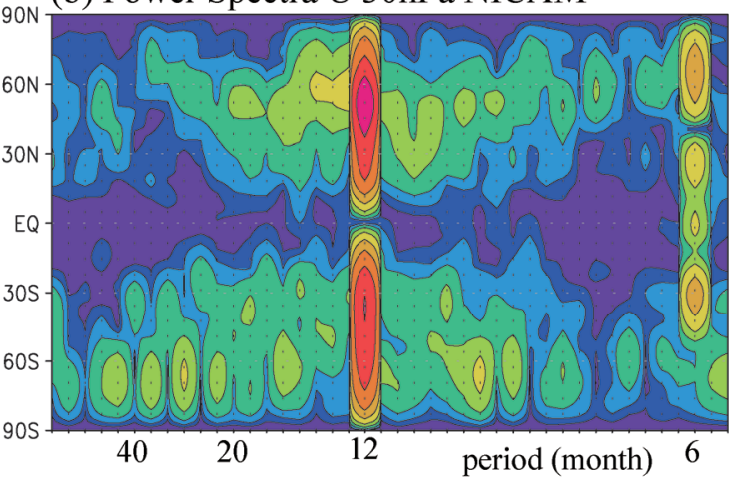

(c) Interannual variability U $30 \mathrm{hPa}$ ERA-I

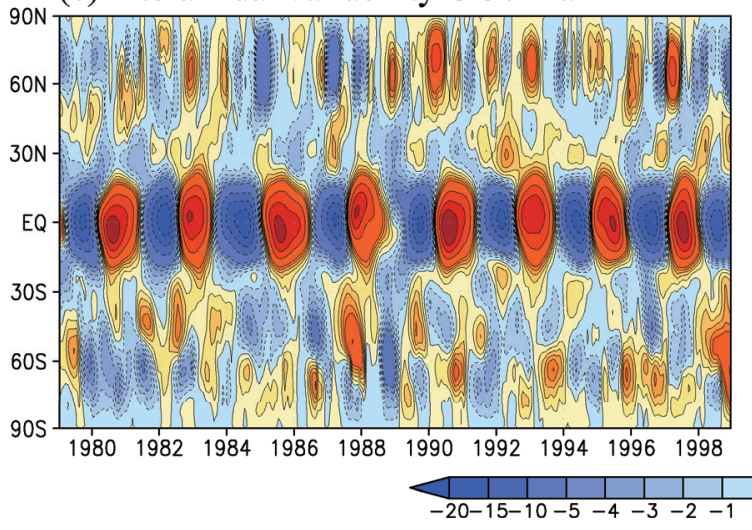

(d) Interannual variability U 30hPa NICAM

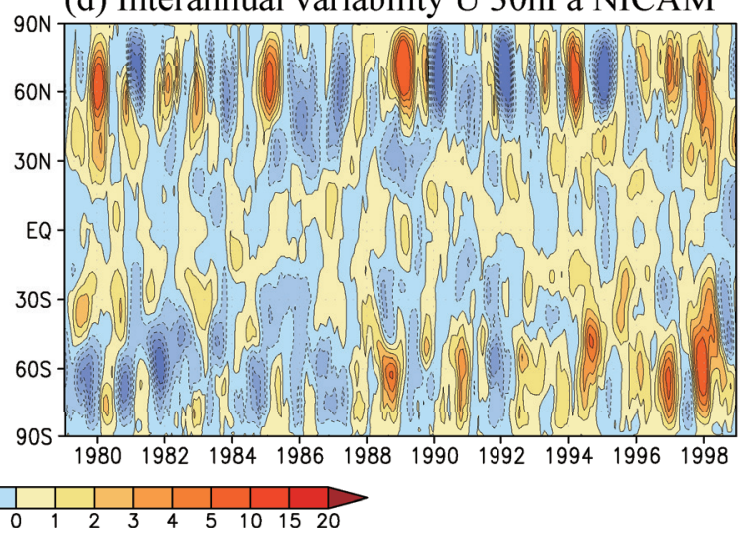

Fig. 19. Frequency power spectra of $30 \mathrm{hPa}$ zonal mean zonal wind in $\mathrm{m}^{2} \mathrm{~s}^{-2}$ month as a function of latitude for ERA-I (a) and NICAM (b) results. Time-latitude cross-section of the interannual anomaly of $30 \mathrm{hPa}$ zonal mean zonal wind in $\mathrm{m} \mathrm{s}^{-1}$ is also shown for ERA-I (c) and NICAM (d).

as discussed in Section 3.1. Over the continent, the warmer surface air temperature bias is evident, especially during summer (Section 3.4). This may be related to the stronger monsoonal flow over South Asia (Section 4.3) and rapid northward advancement of the BF, i.e., shorter Baiu season, in East Asia (Section 4.4). Such a temperature bias is related to the underestimated cloud amount and associated weaker SW cooling (Section 3.2). Insufficient simulated MJO amplitude (Section 4.2) is also a common bias among climate models. The delay in the diurnal precipitation peak (Section 4.5) may be partly caused by insufficient spatial resolution. These biases may be quantitatively emphasized due to the lack of model parameter tuning by a series of climate scale experiments. For example, TOA net radiation imbalance (Section 3.2) is relatively large compared with AMIP simulations by other models (Wang and Su 2013).
In the next phase of NICAM climate simulations, orographic gravity wave drag, aerosol, and sophisticated cloud microphysics schemes are planned to be introduced to better reproduce zonal mean basic states. Seiki and Nakajima (2014) developed a double moment cloud microphysics (NDW6) scheme that reduced the warmer temperature bias in the tropical upper troposphere in the NICAM simulation (Seiki et al. 2015a). Another cloud microphysics scheme choice is the modified NSW6 scheme proposed by Roh and Satoh (2014), which can reproduce better cloud statistics compared with the original one. As stated in Section 2.1, we adopted a slab ocean model, nudged toward observed SSTs rather than fixed SST conditions, to obtain a better geographic precipitation distribution (Appendix A) and the MJO. However, nudging the model in this way causes SST drift from its boundary conditions. The flux correction method, 
such as McFarlane et al. (1992), may be necessary to avoid this problem.

\section{Conclusion}

This study evaluates 20-year climatological mean state and variability simulated by a $14-\mathrm{km}$ mesh NICAM. NICAM reasonably simulates many aspects of atmospheric climatology and variability. The geographical distributions of precipitation, including ENSO related, seasonal, and diurnal variations are reasonably reproduced (Sections 3.1 and 4.5). Simulated zonal mean temperature, zonal wind, mean meridional circulation, clouds, and TOA radiation balance are qualitatively simulated, though some severe biases such as underestimated low clouds and shortwave reflection and warmer surface and tropical upper troposphere exist (Sections 3.2-3.4). Note that we tuned model parameters in advance by performing a series of seasonal- or shorter-scale experiments without any prior climate scale experiments with 14 km mesh NICAM.

The analysis of the individual phenomena in Section 4 also revealed a potential for NICAM to simulate multiscale atmospheric phenomena, especially TCs and the MJO. TCs are captured with objective thresholds of maximum wind speed due to the realistic intensity of simulated TCs. The seasonal march of TC genesis in each ocean basin, as well as TC intensity, is well simulated (Section 4.1). These results are obtained without any cumulus convection scheme, and future TC projection is expected to be more reliable if NICAM is performed under the warmer climate conditions. Wavenumber-frequency power spectrum analysis for the tropical disturbances shows that the MJO and tropical waves are well reproduced (Section 4.2). This implies, based on how tropical waves influence the stratosphere, the stratospheric variability is also well reproduced, as partly revealed in Section 4.6. Asian monsoon analysis shows that climatological western North Pacific monsoon onset agrees closely with the observations (Section 4.3), and that the BF is reproduced to some extent (Section 4.4). Some significant model biases still exist, which indicates a need for further model improvements. The topics chosen here are subjective and not comprehensive but may provide insights into model capabilities. Given the NICAM's ability to explicitly resolve multiple multiscale atmospheric phenomena at a time, the results shown here warrant further the studies of several weather and climate phenomena and their interactions (e.g., TC genesisMJO, CCEWs-stratospheric dynamics, MJO-diurnal cycle, MJO-ENSO) in a seamless manner.

\section{Acknowledgments}

The authors express their thanks to H. Miura, M. Nakano, T. Seiki, T. Miyakawa, Y.-W. Chen, K. Fukutomi, M. Fujita, and K. Oouchi for their fruitful discussions. They also appreciate R. Mizuta at the Meteorological Research Institute for providing external conditions for the AMIP experiment. Constructive comments from two anonymous reviewers helped improve our manuscript. We thank the providers of the data used in this study. Among them, CMAP precipitation and NOAA OLR data were obtained from http://www.esrl.noaa.gov/psd/, ERA-40 and ERA-I from the European Centre for Medium Range Weather Forecasts (ECMWF), ISCCP data from the National Aeronautics and Space Administration (NASA) Langley Research Center Atmospheric Science Data Center, JRA-25 data from the cooperative research project performed by the Japan Meteorological Agency (JMA) and the Central Research Institute of Electric Power Industry (CRIEPI), and JRA-55 data from the JMA. All the simulations analyzed in this study were performed on the $\mathrm{K}$ computer at the RIKEN Advanced Institute for Computational Science (Proposal number hp120279, hp130010, and hp140219). This study was supported by Strategic Programs for Innovative Research (SPIRE) Field 3 (Projection of Planet Earth Variations for Mitigating Natural Disasters), which is promoted by the Ministry of Education, Culture, Sports, Science and Technology (MEXT), Japan. KK acknowledges the support of NOAA Grant NA130AR4310165 and JAMSTEC through its sponsorship of research activities at the IPRC. School of Ocean and Earth Science and Technology Contribution Number 9422 and International Pacific Research Center Contribution Number 1118. YK acknowledges the support of Japan Society for the Promotion of Science (JSPS) KAKENHI Grant Number 26287117.

\section{Appendix A: Impact of SST nudging on the precipitation bias}

In this study, we employed the slab ocean model nudged toward reference SSTs rather than fixed SST condition. This means that the simulated SSTs are slightly different from the reference SSTs. Figure A1 shows the simulated SST anomaly from the reference SST for each season. In the summer (winter) hemisphere, the simulated SST is higher (lower) than the reference SST by approximately $1.5 \mathrm{~K}$. In addition, the warm bias remains throughout nearly the 


\section{SST [K]: NICAM-HadISST}
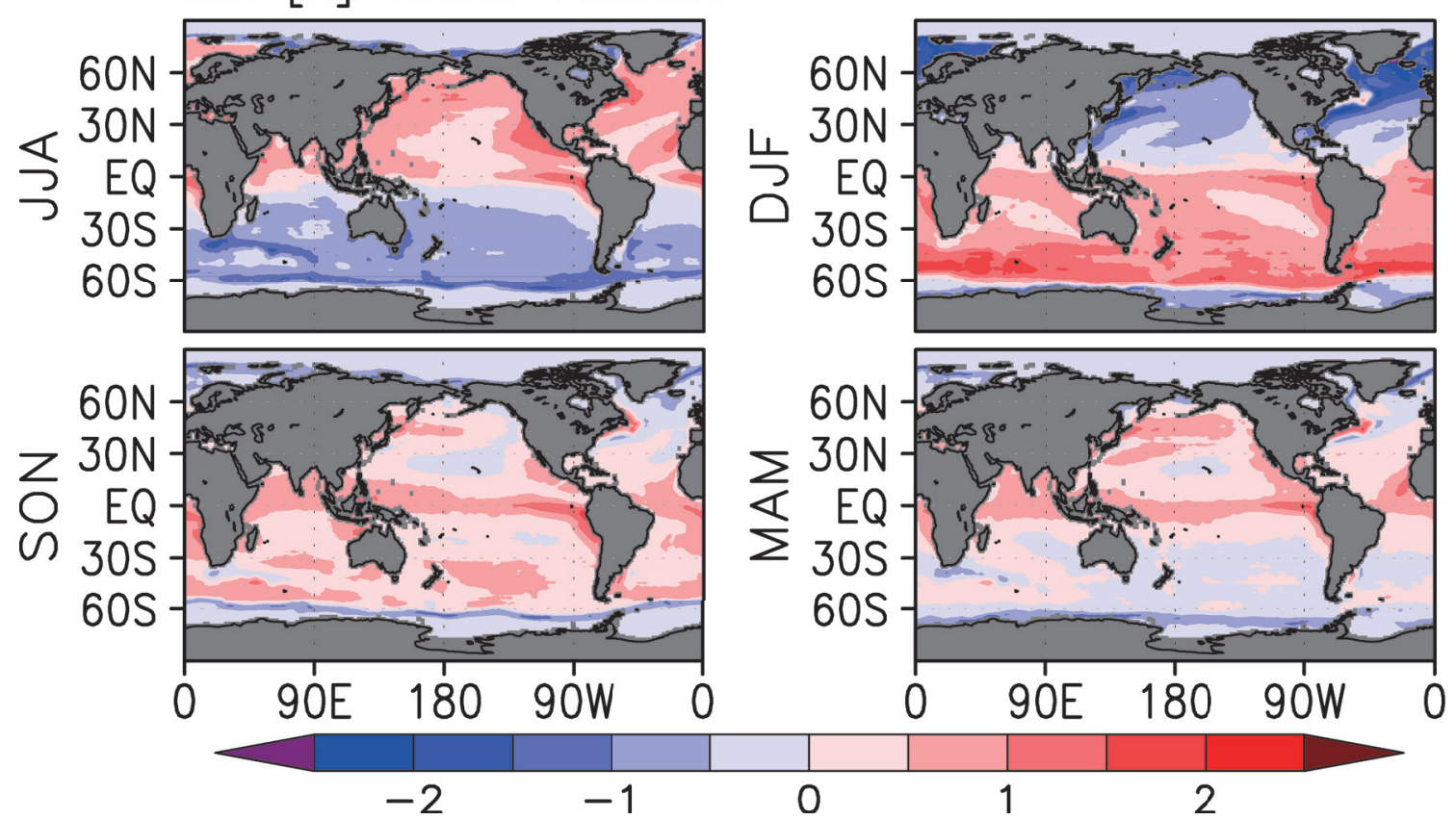

Fig. A1. Seasonal mean climatology of NICAM - HadISST SST in K from March 1979 to February 1999.

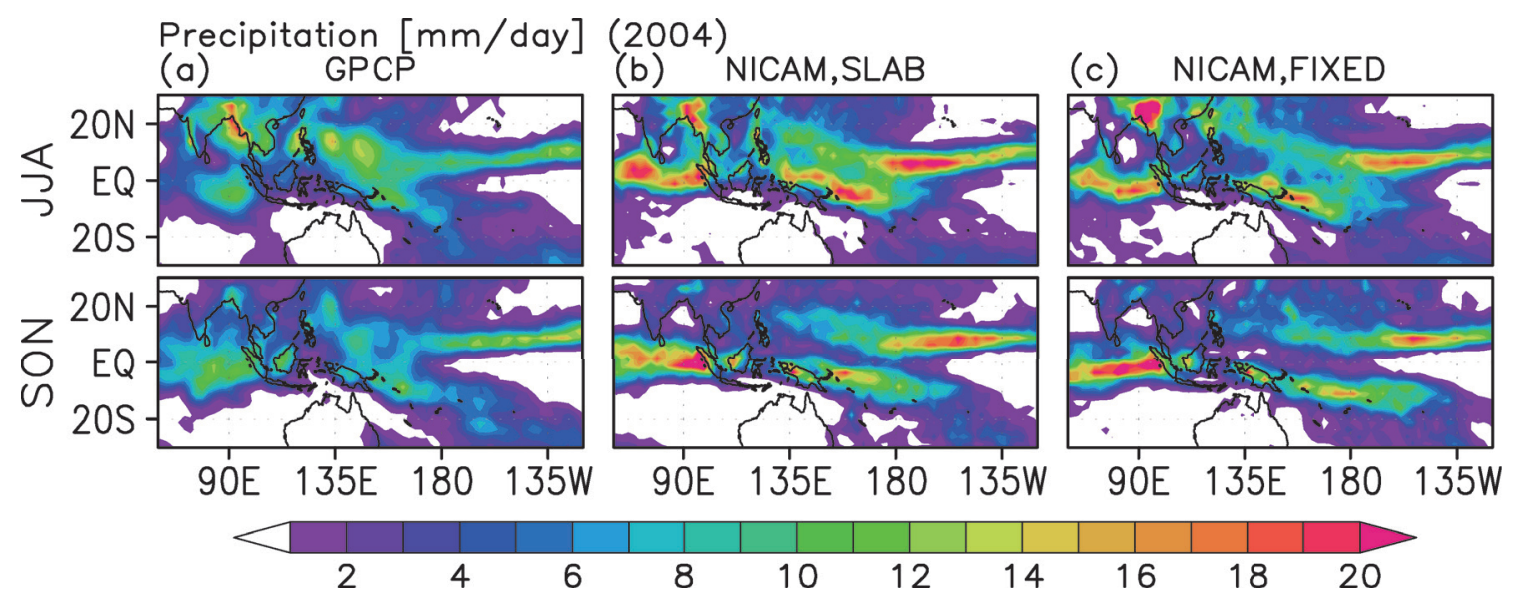

Fig. A2. Seasonal mean precipitation rates in $\mathrm{mm}^{-1} \mathrm{y}^{-1}$ during JJA and SON (2004). GPCP results are shown in (a), NICAM results using the slab ocean model in (b), and NICAM results with fixed SSTs in (c).

entire year in the stratocumulus regions, off the coast of Peru, Namibia, and California, and in the deep tropics, for example, all of which are consistent with the underestimated cloud amount (Fig. 4).

Using the slab ocean model helps to simulate precipitation patterns with less bias than fixed SSTs would produce. Figure A2 shows the precipitation rate over the tropical western Pacific produced by GPCP, NICAM with the slab ocean model (SLAB), and NICAM with the fixed SST (FIXED). These sensitivity experiments began in June 1, 2004, and the integrations were performed for six months. In the FIXED run, dry bias is significant around the Philippines, especially during JJA with a hole-like outline. 
Such a bias is also seen in the SLAB run but with lower magnitude and unclear outline. Though both the FIXED and SLAB runs produce double-ITCZ during SON, the separation of north and south high precipitation regions is clearer in the FIXED run. In addition, precipitation along the coastal areas in the Bay of Bengal is overestimated in the FIXED run. It is beyond the study's scope to determine why the SLAB run reproduces better geographical distributions of precipitation. The relationship between the ocean model and precipitation pattern may be of interest in a cloud system resolving simulation.

\section{References}

Adler, R. F., G. J. Huffman, A. Chang, R. Ferraro, P. P. Xie, J. Janowiak, B. Rudolf, U. Schneider, S. Curtis, D. Bolvin, A. Gruber, J. Susskind, P. Arkin, and E. Nelkin, 2003: The version-2 global precipitation climatology project (GPCP) monthly precipitation analysis (1979-present). J. Hydrometeor., 4, 11471167.

Baldwin, M. P., and T. J. Dunkerton, 2001: Stratospheric harbingers of anomalous weather regimes. Science, 294, 581-584.

Baldwin, M. P., L. J. Gray, T. J. Dunkerton, K. Hamilton, P. H. Haynes, W. J. Randel, J. R. Holton, M. J. Alexander, I. Hirota, T. Horinouchi, D. B. A. Jones, J. S. Kinnersley, C. Marquardt, K. Sato, and M. Takahashi, 2001: The quasi-biennial oscillation. Rev. Geophys., 39, 179-229.

Camargo, S. J., 2013: Global and regional aspects of tropical cyclone activity in the CMIP5 models. $J$. Climate, 26, 9880-9902.

Cess, R. D., G. L. Potter, J. P. Blanchet, G. J. Boer, S. J. Ghan, J. T. Kiehl, H. Letreut, Z. X. Li, X. Z. Liang, J. F. B. Mitchell, J. J. Morcrette, D. A. Randall, M. R. Riches, E. Roeckner, U. Schlese, A. Slingo, K. Taylor, W. M. Washington, R. T. Wetherald, and I. Yagai, 1989: Interpretation of cloud-climate feedback as produced by 14 atmospheric general-circulation models. Science, 245, 513-516.

Chen, T.-C., J.-D. Tsay, M.-C. Yen, and J. Matsumoto, 2012: Interannual variation of the late fall rainfall in central Vietnam. J. Climate, 25, 392-413.

Chu, J.-H., C. R. Sampson, A. S. Levine, and E. Fukada, 2002: The joint typhoon warning center tropical cyclone best-tracks, 1945-2000. Naval Research Laboratory Rep., NRL/MR/7540-02-16, 22 pp.

Dai, A., 2006: Precipitation characteristics in eighteen coupled models. J. Climate, 19, 4605-4630.

Dai, A., and K. E. Trenberth, 2004: The diurnal cycle and its depiction in the Community Climate System Model. J. Climate, 17, 930-951.

Dee, D. P., S. M. Uppala, A. J. Simmons, P. Berrisford, P. Poli, S. Kobayashi, U. Andrae, M. A. Balmaseda, G.
Balsamo, P. Bauer, P. Bechtold, A. C. M. Beljaars, L. van de Berg, J. Bidlot, N. Bormann, C. Delsol, R. Dragani, M. Fuentes, A. J. Geer, L. Haimberger, S. B. Healy, H. Hersbach, E. V. Holm, L. Isaksen, P. Kallberg, M. Kohler, M. Matricardi, A. P. McNally, B. M. Monge-Sanz, J.-J. Morcrette, B.-K. Park, C. Peubey, P. de Rosnay, C. Tavolato, J.-N. Thepaut, and F. Vitart, 2011: The ERA-Interim reanalysis: configuration and performance of the data assimilation system. Quart. J. Roy. Meteor. Soc., 137, 553-597.

Dirmeyer, P. A., B. A. Cash, J. L. Kinter III, T. Jung, L. Marx, M. Satoh, C. Stan, H. Tomita, P. Towers, N. Wedi, D. Achuthavarier, J. M. Adams, E. L. Altshuler, B. Huang, E. K. Jin, and J. Manganello, 2011: Simulating the diurnal cycle of rainfall in global climate models: resolution versus parameterization. Climate Dyn., 39, 399-418.

Ebita, A., S. Kobayashi, Y. Ota, M. Moriya, R. Kumabe, K. Onogi, Y. Harada, S. Yasui, K. Miyaoka, K. Takahashi, H. Kamahori, C. Kobayashi, H. Endo, M. Soma, Y. Oikawa, and T. Ishimizu, 2011: The Japanese 55-year reanalysis "JRA-55": An interim report. SOLA, 7, 149-152.

Emanuel, K. A., 2013: Downscaling CMIP5 climate models shows increased tropical cyclone activity over the 21st century. PNAS, 30, 12219-12224.

Eyring, V., M. P. Chipperfield, M. A. Giorgetta, D. E. Kinnison, E. Manzini, K. Matthes, P. A. Newman, S. Pawson, T. G. Shepherd, and D. W. Waugh, 2008: Overview of the new CCMVal reference and sensitivity simulations in support of upcoming ozone and climate assessments and the planned SPARC CCMVal report. SPARC Newsl., 30, 20-26.

Fairall, C. W., E. F. Bradley, J. E. Hare, A. A. Grachev, and J. B. Edson, 2003: Bulk parameterization of air-sea fluxes: Updates and verification for the COARE algorithm. J. Climate, 16, 571-591.

Fudeyasu, H., Y. Q. Wang, M. Satoh, T. Nasuno, H. Miura, and W. Yanase, 2008: Global cloud-system-resolving model NICAM successfully simulated the lifecycles of two real tropical cyclones. Geophys. Res. Lett., 35, L22808, doi:10.1029/2008GL036003.

Fujita, M., K. Yoneyama, S. Mori, T. Nasuno, and M. Satoh, 2011: Diurnal convection peaks over the eastern Indian Ocean off Sumatra during different MJO phases. J. Meteor. Soc. Japan, 89A, 317-330.

Gates, W. L., 1992: AMIP - The atmospheric model intercomparison project. Bull. Amer. Meteor. Soc., 73, 1962-1970.

Grabowski, W. W., 1998: Toward cloud resolving modeling of large-scale tropical circulations: A simple cloud microphysics parameterization. J. Atmos. Sci., 55, 3283-3298.

Grabowski, W. W., 2001: Coupling cloud processes with the large-scale dynamics using the Cloud-Resolving Convection Parameterization (CRCP). J. Atmos. Sci., 
58, 978-997.

Grabowski, W. W., 2006: Impact of explicit atmosphere-ocean coupling on MJO-like coherent structures in idealized aquaplanet simulations. J. Atmos. Sci., 63, 2289-2306.

Hansen, J., and M. Sato, 2004: Greenhouse gas growth rates. Proc. Natl. Acad. Sci. USA, 101, 16109-16114.

Hara, M, T. Yoshikane, H. G. Takahashi, F. Kimura, A. Noda, and T. Tokioka, 2009: Assessment of the diurnal cycle of precipitation over the Maritime Continent simulated by $20-\mathrm{km}$ mesh GCM using TRMM PR data. J. Meteor. Soc. Japan, 87A, 413-424.

Hodges, K. I., D. W. Chappell, G. J. Robinson, and G. Yang, 2000: An improved algorithm for generating global window brightness temperatures from multiple satellite infrared imagery. J. Atmos. Oceanic Technol, 17, 1296-1312.

Holloway, C. E., S. J. Woolnough, and G. M. S. Lister, 2013: The effects of explicit versus parameterized convection on the MJO in a large-domain high-resolution tropical case study. Part I: Characterization of large-scale organization and propagation. J. Atmos. Sci., 70, 1342-1369.

Holland, G, J., 1995; Scale interaction in the western Pacific monsoon. Meteor. Atmos. Phys., 56, 57-79.

Hung, M. P., J. L. Lin, W. Q. Wang, D. Kim, T. Shinoda, and S. J. Weaver, 2013: MJO and convectively coupled equatorial waves simulated by CMIP5 climate models. J. Climate, 26, 6185-6214.

Iguchi, T., T. Kozu, R. Meneghini, J. Awaka, and K. Okamoto, 2000: Rain-profiling algorithm for the TRMM precipitation radar. J. Appl. Meteor, 39, 2038-2052.

Inness, P. M., J. M. Slingo, E. Guilyardi, and J. Cole, 2003: Simulation of the Madden-Julian oscillation in a coupled general circulation model. Part II: The role of the basic state. J. Climate, 16, 365-382.

Iwasaki, T., 1989: A diagnostic formulation for wave-mean flow interactions and Lagrangian-mean circulation with a hybrid vertical coordinate of pressure and isentropes. J. Meteor. Soc. Japan, 67, 293-312.

Iwasaki, T., H. Hamada, and K. Miyazaki, 2009: Comparisons of Brewer-Dobson circulations diagnosed from reanalyses. J. Meteor. Soc. Japan, 87, 997-1006.

Jarvinen, B. R., C. J. Neumann, and M. A. S. Davis, 1984: A tropical cyclone data tape for the North Atlantic basin, 1886-1983: Contents, limitations and uses. NOAA Tech. Memo., NWS NHC-22, 21 pp.

Kawatani, Y., and K. Hamilton, 2013: Weakened stratospheric quasibiennial oscillation driven by increased tropical mean upwelling. Nature, 497, 478-481.

Kawatani, Y., M. Takahashi, K. Sato, S. P. Alexander, and T. Tsuda, 2009: Global distribution of atmospheric waves in the equatorial upper troposphere and lower stratosphere: AGCM simulation of sources and propagation. J. Geophys. Res, 114, D01102, doi:10.1029/2008JD010374.

Kawatani, Y., K. Sato, T. J. Dunkerton, S. Watanabe, S. Miyahara, and M. Takahashi, 2010: The roles of equatorial trapped waves and internal inertia-gravity waves in driving the quasi-biennial oscillation. Part I: Zonal mean wave forcing. J. Atmos. Sci. 67, 963-980.

Khairoutdinov, M. F., and D. A. Randall, 2001: A cloud resolving model as a cloud parameterization in the NCAR Community Climate System Model: Preliminary results. Geophys. Res. Lett., 28, 3617-3620.

Khairoutdinov, M., C. DeMott, and D. Randall, 2008: Evaluation of the simulated interannual and subseasonal variability in an AMIP-Style simulation using the CSU multiscale modeling framework. J. Climate, 21, 413-431.

Kikuchi, K., 2014: An introduction to combined Fourier-wavelet transform and its application to convectively coupled equatorial waves. Climate. Dyn., 1339-1356.

Kikuchi, K., B. Wang, and Y. Kajikawa, 2012: Bimodal representation of the tropical intraseasonal oscillation. Climate Dyn., 38, 1989-2000.

Kikuchi, K., C. Kodama, T. Nasuno, H. Miura, and M. Satoh, 2015: Tropical intraseasonal oscillation in an AMIP-type experiment by NICAM. J. Adv. Model. Earth Syst., in revision.

Kiladis, G. N., M. C. Wheeler, P. T. Haertel, K. H. Straub, and P. E. Roundy, 2009: Convectively coupled equatorial waves. Rev. Geophys., 47, RG2003, doi:10.1029/2008RG000266.

Kiladis, G. N., J. Dias, K. H. Straub, M. C. Wheeler, S. N. Tulich, K. Kikuchi, K. M. Weickmann, and M. J. Ventrice, 2014: A comparison of OLR and circulation-based indices for tracking the MJO. Mon. Wea. Rev., 142, 1697-1715.

Kim, D., K. Sperber, W. Stern, D. Waliser, I. S. Kang, E. Maloney, W. Wang, K. Weickmann, J. Benedict, M. Khairoutdinov, M. I. Lee, R. Neale, M. Suarez, K. Thayer-Calder, and G. Zhang, 2009: Application of MJO simulation diagnostics to climate models. $J$. Climate, 22, 6413-6436.

Kinter, J. L., B. Cash, D. Achuthavarier, J. Adams, E. Altshuler, P. Dirmeyer, B. Doty, B. Huang, E. K. Jin, L. Marx, J. Manganello, C. Stan, T. Wakefield, T. Palmer, M. Hamrud, T. Jung, M. Miller, P. Towers, N. Wedi, M. Satoh, H. Tomita, C. Kodama, T. Nasuno, K. Oouchi, Y. Yamada, H. Taniguchi, P. Andrews, T. Baer, M. Ezell, C. Halloy, D. John, B. Loftis, R. Mohr, and K. Wong, 2013: Revolutionizing climate modeling with project Athena: A multi-institutional, international collaboration. Bull. Amer. Meteor. Soc., 94, 231-245.

Klein, S. A., and C. Jakob, 1999: Validation and sensitivities of frontal clouds simulated by the ECMWF model. Mon. Wea. Rev., 127, 2514-2531. 
Kodama, C., A. T. Noda, and M. Satoh, 2012: An assessment of the cloud signals simulated by NICAM using ISCCP, CALIPSO, and CloudSat satellite simulators. J. Geophys. Res., 117, D12210, doi:10.1029/2011JD017317.

Knapp, K. R., M. C. Kruk, D. H. Levinson, H. J. Diamond, and C. J. Neumann, 2010: The International Best Track Archive for Climate Stewardship (IBTrACS). Bull. Amer. Meteor. Soc., 91, 363-376.

Lau, K. M., H. T. Wu, and S. Bony, 1997: The role of largescale atmospheric circulation in the relationship between tropical convection and sea surface temperature. J. Climate, 10, 381-392.

Liebmann, B., and C. A. Smith, 1996: Description of a complete (interpolated) outgoing longwave radiation dataset. Bull. Amer. Meteor. Soc., 77, 1275-1277.

Loeb, N. G., B. A. Wielicki, D. R. Doelling, G. L. Smith, D. F. Keyes, S. Kato, N. Manalo-Smith, and T. Wong, 2009: Toward optimal closure of the Earth's top-of-atmosphere radiation budget. J. Climate, 22, 748-766.

Louis, J. F., 1979: A parametric model of vertical eddy fluxes in the atmosphere. Bound.-Layer Meteor., 17, 187-202.

Love, B. S., A. J. Matthews, and G. M. S. Lister, 2011: The diurnal cycle of precipitation over the Maritime Continent in a high-resolution atmospheric model. Quart. J. Roy. Meteor. Soc., 137, 934-947.

Madden, R. A., and P. R. Julian, 1971: Detection of a 40-50 day oscillation in the zonal wind in the tropical Pacific. J. Atmos. Sci., 28, 702-708.

Madden, R. A., and P. R. Julian, 1972: Description of global-scale circulation cells in tropics with a 40-50 day period. J. Atmos. Sci., 29, 1109-1123.

Manganello, J. V., K. I. Hodges, J. L. Kinter III, B. A. Cash, L. Marx, T. Jung, D. Achuthavarier, J. M. Adams, E. L. Altshuler, B. Huang, E. K. Jin, C. Stan, P. Towers, and N. Wedi, 2012: Tropical cyclone climatology in a 10-km global atmospheric GCM: Toward weather-resolving climate modeling. J. Climate, 25, 3867-3893.

Manganello, J. V., K. I. Hodges, B. Dirmeyer, J. L. Kinter III, B. A. Cash, L. Marx, T. Jung, D. Achuthavarier, J. M. Adams, E. L. Altshuler, B. Huang, E. K. Jin, P. Towers, and N. Wedi, 2014: Future changes in the western North Pacific tropical cyclone activity projected by a multidecadal simulation with a $16-\mathrm{km}$ global atmospheric GCM. J. Climate, 27, 7622-7644.

Mass, C. F., D. Ovens, K. Westrick, and B. A. Colle, 2002: Does increasing horizontal resolution produce more skillful forecasts? Bull. Amer. Meteor. Soc., 83, 407-430.

Matsueda, M., and H. Endo, 2011: Verification of medium-range MJO forecasts with TIGGE. Geophys. Res. Lett., 38, L11801, doi:10.1029/2011GL047480.

Matsuno, T., 1966: Quasi-geostrophic motions in the equatorial area. J. Meteor. Soc. Japan, 44, 25-43.

McFarlane, N. A., 1987: The effect of orographically excited gravity-wave drag on the general-circulation of the lower stratosphere and troposphere. J. Atmos. Sci., 44, 1775-1800.

McFarlane, N. A., G. J. Boer, J.-P. Blanchet, and M. Lazare, 1992: The Canadian Climate Centre second-generation general circulation model and its equilibrium climate. J. Climate, 5, 1013-1044.

Miura, H., M. Satoh, T. Nasuno, A. T. Noda, and K. Oouchi, 2007: A Madden-Julian oscillation event realistically simulated by a global cloud-resolving model. Science, 318, 1763-1765.

Miyakawa, T., M. Satoh, H. Miura, H. Tomita, H. Yashiro, A. T. Noda, Y. Yamada, C. Kodama, M. Kimoto, and K. Yoneyama, 2014: Madden-Julian Oscillation prediction skill of a new-generation global model demonstrated using a supercomputer. Nature Commun., 5, 3769, doi:10.1038/ncomms4769.

Miyamoto, Y., Y. Kajikawa, R. Yoshida, T. Yamaura, H. Yashiro, and H. Tomita, 2013: Deep moist atmospheric convection in a subkilometer global simulation. Geophys. Res. Lett., 40, 4922-4926.

Miyamoto, Y., M. Satoh, H. Tomita, K. Oouchi, Y. Yamada, C. Kodama, and J. Kinter, 2014: Gradient wind balance in tropical cyclones in high-resolution global experiments. Mon. Wea. Rev., 142, 1908-1926.

Miyazaki, H., Y. Kusano, H. Okano, T. Nakada, K. Seki, T. Shimizu, N. Shinjo, F. Shoji, A. Uno, and M. Kurokawa, 2012: K computer: 8.162 PetaFLOPS massively parallel scalar supercomputer built with over 548k cores. Solid-State Circuits Conference Digest of Technical Papers (ISSCC), 2012 IEEE International, IEEE, 192-194.

Mizuta, R., K. Oouchi, H. Yoshimura, A. Noda, K. Katayama, S. Yukimoto, M. Hosaka, S. Kusunoki, H. Kawai, and M. Nakagawa, 2006: 20-km-mesh global climate simulations using JMA-GSM model - mean climate states. J. Meteor. Soc. Japan, 84, 165-185.

Mizuta, R., Y. Adachi, S. Yukimoto, and S. Kusunoki, 2008: Estimation of the future distribution of sea surface temperature and sea ice using the CMIP3 multimodel ensemble mean. Tech. Rep. Meteorol. Res. Inst., 56, 1-28.

Mizuta, R., H. Yoshimura, H. Murakami, M. Matsueda, H. Endo, T. Ose, K. Kamiguchi, M. Hosaka, M. Sugi, S. Yukimoto, S. Kusunoki, and A. Kitoh, 2012: Climate simulations using MRI-AGCM3.2 with 20-km grid. $J$. Meteor. Soc. Japan, 90A, 233-258.

Moon, I. J., I. Ginis, T. Hara, and B. Thomas, 2007: A physics-based parameterization of air-sea momentum flux at high wind speeds and its impact on hurricane intensity predictions. Mon. Wea. Rev., 135, 2869-2878.

Murakami, H., and M. Sugi, 2010: Effect of model resolution on tropical cyclone climate projection. SOLA, 6 , 73-76.

Murakami, H., Y. Wang, H. Yoshimura, R. Mizuta, M. Sugi, E. Shindo, Y. Adachi, S. Yukimoto, M. Hosaka, S. 
Kusunoki, T. Ose, and A. Kitoh, 2012: Future change in tropical cyclone activity projected by the new high-resolution MRI-AGCM. J. Climate, 25, 32373260 .

Murakami, T., and J. Matsumoto, 1994: Summer monsoon over the Asian Continent and western North Pacific. J. Meteor. Soc. Japan, 72, 719-745.

Nakanishi, M., and H. Niino, 2006: An improved Mellor-Yamada level-3 model: Its numerical stability and application to a regional prediction of advection fog. Bound.-Layer Meteor, 119, 397-407.

Nguyen, H., A. Evans, C. Lucas, I. Smith, and B. Timbal, 2013: The Hadley circulation in reanalyses: climatology, variability, and change. J. Climate, 26, 33573376.

Noda, A. T., K. Oouchi, M. Satoh, H. Tomita, S. Iga, and Y. Tsushima, 2010: Importance of the subgridscale turbulent moist process: Cloud distribution in global cloud-resolving simulations. Atmos. Res., 96, 208-217.

Noda, A. T., K. Oouchi, M. Satoh, and H. Tomita, 2012: Quantitative assessment of diurnal variation of tropical convection simulated by a global nonhydrostatic model without cumulus parameterization. J. Climate, 25, 5119-5134.

Onogi, K., J. Tsutsui, H. Koide, M. Sakamoto, S. Kobayashi, H. Hatsushika, T. Matsumoto, N. Yamazaki, H. Kamahori, K. Takahashi, S. Kadokura, K. Wada, K. Kato, R. Oyama, T. Ose, N. Mannoji, and R. Taira, 2007: The JRA-25 reanalysis. J. Meteor. Soc. Japan, 85, 369-432.

Oouchi, K., J. Yoshimura, H. Yoshimura, R. Mizuta, S. Kusunoki, and A. Noda, 2006: Tropical cyclone climatology in a global-warming climate as simulated in a $20 \mathrm{~km}$-mesh global atmospheric model: Frequency and wind intensity analyses. J. Meteor. Soc. Japan, 84, 259-276.

Oouchi, K., A. T. Noda, M. Satoh, H. Miura, H. Tomita, T. Nasuno, and S. Iga, 2009: A simulated preconditioning of typhoon genesis controlled by a boreal summer Madden-Julian Oscillation event in a global cloud-system-resolving model. SOLA, 5, 65-68.

Pauluis, O., and S. Garner, 2006: Sensitivity of radiative-convective equilibrium simulations to horizontal resolution. J. Atmos. Sci., 63, 1910-1923.

Petch, J. C., A. R. Brown, and M. E. B. Gray, 2002: The impact of horizontal resolution on the simulations of convective development over land. Quart. J. Roy. Meteor. Soc., 128, 2031-2044.

Rayner, N. A., D. E. Parker, E. B. Horton, C. K. Folland, L. V. Alexander, D. P. Rowell, E. C. Kent, and A. Kaplan, 2003: Global analyses of sea surface temperature, sea ice, and night marine air temperature since the late nineteenth century. J. Geophys. Res., 108, 4407, doi:10.1029/2002JD002670.

Ritchie, E. A., and G. J. Holland, 1999: Large-scale patterns associated with tropical cyclogenesis in the western Pacific. Mon. Wea. Rev., 127, 2027-2043.

Roberts, M. J., P. L. Vidale, M. S. Mizielinski, M. E. Demory, R. Schiemann, J. Strachan, K. Hodges, R. Bell, and J. Camp, 2015: Tropical cyclones in the UPSCALE ensemble of high-resolution global climate models. J. Climate, 28, 574-596.

Roh, W., and M. Satoh, 2014: Evaluation of precipitating hydrometeor parameterizations in a single-moment bulk microphysics scheme for deep convective systems over the tropical central pacific. J. Atmos. Sci., 71, 2654-2673.

Rossow, W. B., and R. A. Schiffer, 1999: Advances in understanding clouds from ISCCP. Bull. Amer. Meteor. Soc., 80, 2261-2287.

Saito, N., 1966: A preliminary study of the summer monsoon of southern and eastern Asia. J. Meteor. Soc. Japan, 44, 44-59.

Sato, T., H. Miura, M. Satoh, Y. N. Takayabu, and Y. Q. Wang, 2009: Diurnal cycle of precipitation in the tropics simulated in a global cloud-resolving model. J. Climate, 22, 4809-4826.

Satoh, M., T. Matsuno, H. Tomita, H. Miura, T. Nasuno, and S. Iga, 2008: Nonhydrostatic icosahedral atmospheric model (NICAM) for global cloud resolving simulations. J. Comput. Phys., 227, 3486-3514.

Satoh, M., K. Oouchi, T. Nasuno, H. Taniguchi, Y. Yamada, H. Tomita, C. Kodama, J. Kinter III, D. Achuthavarier, J. Manganello, B. Cash, T. Jung, T. Palmer, and N. Wedi, 2012: The intra-seasonal oscillation and its control of tropical cyclones simulated by high-resolution global atmospheric models. Climate. Dyn., 39, 2185-2206.

Satoh, M., H. Tomita, H. Yashiro, H. Miura, C. Kodama, T. Seiki, A. T. Noda, Y. Yamada, D. Goto, M. Sawada, T. Miyoshi, Y. Niwa, M. Hara, T. Ohno, S. Iga, T. Arakawa, T. Inoue, and H. Kubokawa, 2014: The non-hydrostatic icosahedral atmospheric model: Description and development. Prog. Earth Planet. Sci., 1, 18, doi:10.1186/s40645-014-0018-1.

Satomura, T., 2000: Diurnal variation of precipitation over the Indo-China Peninsula: Two-dimensional numerical simulation. J. Meteor. Soc. Japan, 78, 461-475.

Seiki, T., and T. Nakajima, 2014: Aerosol effects of the condensation process on a convective cloud simulation. J. Atmos. Sci., 71, 833-853.

Seiki, T., C. Kodama, A. T. Noda, and M. Satoh, 2015a: Impacts of a double-moment bulk cloud microphysics scheme on global cloud-system resolving simulation. J. Climate, 28, 2405-2419.

Seiki, T., C. Kodama, M. Satoh, T. Hashino, Y. Hagihara, and H. Okamoto, 2015b: Vertical grid spacing necessary for simulating tropical cirrus clouds with a high-resolution AGCM. Geophys. Res. Lett, 41504157.

Sekiguchi, M., and T. Nakajima, 2008: A k-distribu- 
tion-based radiation code and its computational optimization for an atmospheric general circulation model. J. Quant. Spectrosc. Radiat. Transfer, 109, 2779-2793.

Serra, Y. L., G. N. Kiladis, and K. I. Hodges, 2010: Tracking and mean structure of easterly waves over the Intra-Americas Sea. J. Climate, 23, 4823-4840.

Shibata, K., M. Deushi, T. T. Sekiyama, and H. Yoshimura, 2004: Development of an MRI chemical transport model for the study of stratospheric chemistry. Pap. Meteor. Geophys., 55, 75-119.

Shukla, J., R. Hagedorn, B. Hoskins, J. Kinter, J. Marotzke, M. Miller, T. N. Palmer, and J. Slingo, 2009: Revolution in climate prediction is both necessary and possible a declaration at the world modelling summit for climate prediction. Bull. Amer. Meteor. Soc., 90, $175-178$.

Soden, B. J., and I. M. Held, 2006: An assessment of climate feedbacks in coupled ocean-atmosphere models. J. Climate, 19, 3354-3360.

Sperber, K. R., and H. Annamalai, 2008: Coupled model simulations of boreal summer intraseasonal (30-50 day) variability, Part 1: Systematic errors and caution on use of metrics. Climate Dyn., 31, 345-372.

Sperber, K., H. Annamalai, I. S. Kang, A. Kitoh, A. Moise, A. Turner, B. Wang, and T. Zhou, 2013: The Asian summer monsoon: an intercomparison of CMIP5 vs. CMIP3 simulations of the late 20th century. Climate Dyn., 41, 2711-2744.

Stevens, B., and S. Bony, 2013: What are climate models missing? Science, 340, 1053-1054.

Sugi, M., A. Noda, and N. Sato, 2002: Influence of the global warming on tropical cyclone climatology: An experiment with the JMA global model. J. Meteor. Soc. Japan, 80, 249-272.

Takahashi, H. G., H. Fujinami, T. Yasunari, and J. Matsumoto, 2010: Diurnal rainfall pattern observed by Tropical Rainfall Measuring Mission Precipitation Radar (TRMM-PR) around the Indochina peninsula. J. Geophys. Res., 115, D07109, doi:10.1029/2009JD012155.

Takata, K., S. Emori, and T. Watanabe, 2003: Development of the minimal advanced treatments of surface interaction and runoff. Global. Planet. Change, 38, 209-222.

Taniguchi, H., W. Yanase, and M. Satoh, 2010: Ensemble simulation of cyclone nargis by a global cloud-system-resolving model-modulation of cyclogenesis by the Madden-Julian oscillation. J. Meteor. Soc. Japan, 88, 571-591.

Taylor, K. E., D. Williamson, and F. Zwiers, 2000: The sea surface temperature and sea-ice concentration boundary conditions for AMIP II simulations. Program For Climate Model Diagnosis And Intercomparison (PCMDI) Report, 60, 28 pp.

Tomita, H., 2008: New microphysical schemes with five and six categories by diagnostic generation of cloud ice. $J$. Meteor. Soc. Japan, 86A, 121-142.

Tomita, H., and M. Satoh, 2004: A new dynamical framework of nonhydrostatic global model using the icosahedral grid. Fluid Dyn. Res., 34, 357-400.

Tomita, T., T. Yamaura, and T. Hashimoto, 2011: Interannual variability of the Baiu season near Japan evaluated from the equivalent potential temperature. $J$. Meteor. Soc. Japan, 89, 517-537.

Uppala, S. M., P. W. Kållberg, A. J. Simmons, U. Andrae, V. D. C. Bechtold, M. Fiorino, J. K. Gibson, J. Haseler, A. Hernandez, G. A. Kelly, X. Li, K. Onogi, S. Saarinen, N. Sokka, R. P. Allan, E. Andersson, K. Arpe, M. A. Balmaseda, A. C. M. Beljaars, L. Van De Berg, J. Bidlot, N. Bormann, S. Caires, F. Chevallier, A. Dethof, M. Dragosavac, M. Fisher, M. Fuentes, S. Hagemann, E. Hólm, B. J. Hoskins, L. Isaksen, P. A. E. M. Janssen, R. Jenne, A. P. McNally, J.-F. Mahfouf, J.-J. Morcrette, N. A. Rayner, R. W. Saunders, P. Simon, A. Sterl, K. E. Trenberth, A. Untch, D. Vasiljevic, P. Viterbo, and J. Woollen, 2005: The ERA-40 re-analysis. Quart. J. Roy. Meteor. Soc., 131, 2961-3012.

Vial, J., J. L. Dufresne, and S. Bony, 2013: On the interpretation of inter-model spread in CMIP5 climate sensitivity estimates. Climate Dyn., 41, 3339-3362.

Walsh, K. J. E., M. Fiorino, C. W. Landsea, and L. McInnes, 2007: Objectively determined resolution-dependent threshold criteria for the detection of tropical cyclones in climate models and reanalyses. $J$. Climate, 20, 2307-2314.

Wang, B., 2002: Rainy season of the Asian-Pacific summer monsoon. J. Climate, 15, 386-398.

Wang, B., 2006: The Asian Monsoon. Springer Science \& Business Media, $838 \mathrm{pp}$.

Wang B, R. Wu, and K. M. Lau, 2001: Interannual variability of Asian summer monsoon: Contrast between the Indian and western North Pacific-East Asian monsoons. J. Climate, 14, 4073-4090.

Wang, B., Y.-S. Zhang, and M. M. Lu, 2004: Definition of South China Sea monsoon onset and commencement of the East Asia summer monsoon. J. Climate, 17, 699-710.

Wang, H. L., and W. Y. Su, 2013: Evaluating and understanding top of the atmosphere cloud radiative effects in intergovernmental panel on climate change (IPCC) fifth assessment report (AR5) coupled model intercomparison project phase 5 (CMIP5) models using satellite observations. J. Geophys. Res., 118, 683-699.

Webb, M., C. Senior, S. Bony, and J. J. Morcrette, 2001: Combining ERBE and ISCCP data to assess clouds in the Hadley Centre, ECMWF and LMD atmospheric climate models. Climate Dyn., 17, 905-922.

Wheeler, M., and G. N. Kiladis, 1999: Convectively coupled equatorial waves: Analysis of clouds and temperature in the wavenumber-frequency domain. $J$. 
Atmos. Sci., 56, 374-399.

Xie, P., and P. A. Arkin, 1997: Global precipitation: A 17-year monthly analysis based on gauge observations, satellite estimates, and numerical model outputs. Bull. Amer. Meteor. Soc., 78, 2539-2558.

Yamada, Y., and M. Satoh, 2013: Response of ice and liquid water paths of tropical cyclones to global warming simulated by a global nonhydrostatic model with explicit cloud microphysics. J. Climate, 26, 99319945.

Yokokawa, M., F. Shoji, A. Uno, M. Kurokawa, and T. Watanabe, 2011: The K computer: Japanese next-generation supercomputer development project. Proceedings of the 17th IEEE/ACM international symposium on low-power electronics and design, IEEE Press, 371-372.

Yoshida, R., and H. Ishikawa, 2013: Environmental factors contributing to tropical cyclone genesis over the western North Pacific. Mon. Wea. Rev., 141, 451-467.

Zhao, M., 2014: An investigation of the connections among convection, clouds, and climate sensitivity in a global climate model. J. Climate, 27, 1845-1862.

Zhao, M., and I. M. Held, 2010: An analysis of the effect of global warming on the intensity of atlantic hurricanes using a GCM with statistical refinement. J. Climate, 23, 6382-6393.

Zhao, M., I. M. Held, S.-J. Lin, and G. A. Vecchi, 2009: Simulations of global hurricane climatology, interannual variability, and response to global warming using a 50-km resolution GCM. J. Climate, 22, 6653-6678.

Zhao, M., I. M. Held, and S.-J. Lin, 2012: Some counterintuitive dependencies of tropical cyclone frequency on parameters in a GCM. J. Atmos. Sci., 69, 2272-2283. 